\title{
Elicitation of Strategy Profiles in Large Group
} Coordination Games

\author{
Darryl A. Seale \\ and \\ Amnon Rapoport
}

Series No. MK'TG 99.139

April 27, 1999 


\title{
Elicitation of Strategy Profiles in Large Group \\ Coordination Games
}

\author{
Darryl A. Seale \\ Amnon Rapoport \\ University of Nevada Las Vegas \\ Hong Kong University of \\ Science and Technology
}

April 27. 1999 


\begin{abstract}
The strategy method is an experimental procedure for eliciting a complete strategy of play for all information sets, not only the ones that happen to be reached during the course of a play of a game. We use it to elicit individual strategy profiles for a class of large group, market entry games in which the payoff for a player who enters on a given market capacity value decreases linearly in the difference between this value and the corresponding number of entrants. Our results show that the number of entrants across a large set of market capacity values is organized remarkably well by the equilibrium solution. The results do not differ from previous results obtained under the more common decision method. In contrast, the individual profiles do not support equilibrium play. Rather, they exhibit a variety of patterns that defy any classification. In particular, we find no evidence in support of cutoff decision rules that seem to be elicited under the decision method.
\end{abstract}




\section{Introduction}

The ordinary and traditional way of gathering data in iterated games is by using the decision method, which requires the participating agents to make single decisions at different time periods with information that varies from period to period. This procedure has also been used exclusively in all the social psychological studies of interactive decision behavior. Aware of the possible limitations of this method to provide information on all information sets in the game, not only the ones that are happened to be reached during the course of a play of the game, Selten (1967) proposed an alternative procedure that he called the strategy method. Under the strategy method, the interacting agents are first exposed to a repeated play of the game to provide them some experience. Then they are requested to specify complete strategies of play, independently and anonymously, on the basis of their experience. They do so with the understanding that the strategies they submit will be later pitted one against the other in order to determine their individual payoffs.

The advantages and disadvantages of the strategy method in comparison to the decision method have been discussed hy Mitzkewitz and Nagel (1993), Rapoport and Fuller (1995), and Roth (1995). As pointed out above, the major advantage of the strategy method is its ability to acquire data on all information sets of every player in the game, not just the ones that are actually reached during a play of the game, a play which is determined endogenously by the players' moves or some chance move and is not subject to control and manipulation by the experimenter. Mitzkewitz and Nagel noted that observing the entire strategies of the agents, rather than the moves that actually occur during the game, may provide insight into their motivation. These insights may, in turn, prove to be important in constructing descriptive models of behavior, which frequently incorporate assumptions about unobserved entities like motivation and beliefs of the interacting agents. The obvious disadvantage is that the strategy method removes from the experimental observation the possible effects of the 
timing of decisions in the course of the game (Roth, 1995). This disadvantage was recognized by Selten, Mitzkewitz, and Uhlich, who write: "It would be wrong to assert that there is no difference between a programmed strategy and spontaneous behavior. The strategy method cannot completely reveal the structure of spontaneous behavior" (1997, p. 552). This seems to be particularly the case in a within-subject comparison of the two methods, where the agents are asked to specify their strategies after gaining experience with the game under the decision method. Much of the spontaneity they might have in the first phase of the experiment must have already been dissipated when they are required to specify their complete strategies.

Roth has pointed out another potentially important difference between these two alternative methods of data acquisition. Having to submit complete strategies evokes different cognitive processes, as it forces the agent to think about each information set in a different way than she would think about those information sets that actually arise in the course of the game. Whether this shift in focus may result in outcomes that differ substantially from the ones under the decision method is a methodological question that can only be answered empirically

Previous Studies. The strategy method was first used by Selten (1967) in an iterated oligopoly game with investment and price valuation, and later on by Axelrod (1984) in his study of the Prisoner's Dilemma supergame, and Fader and Hauser (1988) in their investigation of two symmetric price triopolies. Following Selten (1967), Mitzkewitz and Nagel (1993) used the strategy method in their study of two-person ultimatum games with one-sided incomplete information. Basically, they required the two players-the sender and receiver-to submit complete strategies for the game before a six-sided die was thrown to determine the size of the cake to be apportioned between the two players. The sender was requested to submit in advance his offer, depending on the cake size, for each of the six 
possible outcomes of the toss of the die. Without knowing the size of the cake, the receiver was required to indicate whether or not she would accept each of the thirteen possible offers ranging between 0 and 6 in step of 0.5 .

Selten et al. (1997) went a step further by eliciting continuous rather than discrete strategies. Their experiment examined a non-symmetric Cournot duopoly with linear costs and demand functions. Their subjects were students of economics with some experience in computer programming and no training in either price or game theory. Unlike the study by Fader and Hauser (1988), their subjects had an opportunity to participate in the game before submitting their computerized strategies. After participating in the game for three rounds of play under the decision method and publicly discussing the results of each period, the subjects were required to program continuous strategies in PASCAL for a subsequent 20period supergame. All workable programs were then submitted to a tournament that determined the individual payoffs. A possible limitation of this study is that the strategies submitted hy the subjects could be regarded as statistically independent observations, as the subjects interacted in the game playing rounds and tournaments.

In yet another related study with continuous strategy spaces, Selten and Buchta (1999) used the strategy method in a sealed bid first price auction that was iterated for 50 periods. At the beginning of each period, each of the players (in groups of 6,9 , or 12) was requested to specify a piecewise linear bid function (that could include many linear sections) that was actually displayed on a computer screen. The corners of the bid function could be fixed by a graphical input mode or entered numerically. No programming of strategies was required. The computer program then computed the linear connections between adjacent corners and displayed them on the individual screens. Although the bid functions were forced to be piecewise linear, they were not forced to be monotonic. Surprisingly, in contrast to all the game theoretical models proposed in the literature, Selten and Buchta observed many $(46 \%)$ 
non-monotonic bid functions that were actually decreasing over parts of the range. This finding was not limited to the initial phase of the task.

Rapoport and Fuller (1995) used the strategy method in their study of bilateral bargaining under the sealed bid double auction mechanism (see, e.g., Linhart, Radner, \& Satterthwaite, 1989). Their study was motivated by a finding first reported by Radner and Schotter (1988). While studying this mechanism in an iterated two-person bargaining game with a fixed pairing of players, Radner and Schotter (1989), and subsequently Linhart, Radner, and Schotter (1990), reported that as the number of iterations increased, a modified form of step-function equilibrium was observed in which bid strategies of the two traders consisted of two-piece linear functions. Rapoport and Fuller compared the decision and strategy method using again a within-subjects design where the strategy method (administered only once on the last period) followed the decision method. They reported small but consistent differences between the bid functions elicited by the two methods. The functions inferred indirectly from the bids and offers and the ones elicited directly under the strategy method were positively and significantly correlated across the players. However, the latter functions violated monotonicity less frequently and came closer to the linear bid function under truth-telling. These findings are also to be interpreted with caution because experience with the task and data gathering method were confounded in the design.

The conclusion that we draw from this still very limited body of research is that the comparison between the two methods is presently inconclusive. The two methods seem to elicit different outcomes, in line with the observations made by Roth, but the magnitude and type of the differences cannot be presently ascertained. Although it is plausible to assume, as Selten and Buchta do, that a player writing a strategy program is guided by the same motivational forces that influence his spontaneous behavior under the decision method, there is no assurance that the strategy method is likely to yield more orderly and systematic 
response functions. In the study of Rapoport and Fuller, the strategy method did, indeed, yield more systematic bid functions with fewer violations of monotonicity. However, the percentage of non-monotonic bid functions elicited directly by the strategy method in the study of Selten and Buchta is considerably higher than the percentage of non-monotonic bid functions inferred directly from bids and offers in the various studies of the sealed bid double auction mechanism conducted by Radner and Schotter (1988), Daniel, Seale, and Rapoport (1998), and Rapoport, Daniel, and Seale (1999).

The present study shifts the focus of investigation from two-person bargaining and oligopoly to tacit coordination in large groups. Its main purpose is to study coordination under the strategy method in a class of iterated market entry games that was previously studied under the decision method, and to compare to each other these two procedures in a between-subjects design. The study was motivated by a recent finding that the remarkable coordination observed in this class of market entry games is achieved through some sort of adaptive learning process in the following manner. When the market capacity, denoted by $\mathrm{c}$. is common knowledge and its value is varied randomly from period to period, the players' strategies inferred from their decisions converge to cutoff decision rules of the form "enter if and only if $c \geq c^{*}$, with individual values of $c^{*}$ that after many iterations of the game come to be distributed more or less uniformly in the population of players. An adaptive learning model that incorporates this process as its basic assumption organizes the experimental results in a very satisfactory manner. The strategy method is ideally suited to elicit the entire individual strategy profiles directly and examine how they evolve over time, rather than infer them from entry decisions.

The rest of the paper is organized as follows. Section 2 describes the market entry game, characterizes its equilibria, and then summarizes the experimental findings from earlier experiments that are most pertinent to the present study. Section 2 describes the experimental 
method and elicitation of the individual strategy profiles. Section 4 presents the results on both the aggregate and individual levels, and then compares the aggregate results to those obtained under the decision method in a previous market entry experiment with the same game parameters. Section 5 concludes.

\section{The Market Entry Game}

\section{The MEFC Game}

The market entry with fixed capacity (MEFC) game is a non-cooperative n-person game played by a group $\mathrm{N}$ of $\mathrm{n}$ players for $\mathrm{T}$ periods. At the beginning of each period $\mathrm{t}(\mathrm{t}=$ $1,2, \ldots, T)$, a (possibly different) positive integer $\mathrm{c}(1 \leq \mathrm{c} \leq \mathrm{n})$, interpreted as the "capacity of the market", is publicly announced. Then, each player $i(i \in N)$ is privately notified of her entry fee, denoted by $h_{i}$, for the period. The values of $T$ and $n$ as well as the distribution of the entry fees $h_{i}$ are assumed to be common knowledge. Once the value of $c$ is commonly known, each player i must decide privately and independently whether to enter the market $\left(d_{i}\right.$ $=1)$ or stay out of it $\left(d_{i}=0\right)$. Communication before or during the game is strictly prohibited. Denote the actual number of entrants by $m(0 \leq m \leq n)$. Individual payoffs, denoted by $\mathrm{H}_{\mathrm{i}}(\mathbf{d})$ are computed from

$$
\mathrm{v}, \quad \text { if } \mathrm{d}_{\mathrm{i}}=0
$$

$$
\begin{aligned}
& H_{i}(\mathbf{d})= \\
& k+r(m-c), \quad \text { if } d_{i}=1,
\end{aligned}
$$

where $\mathrm{v}, \mathrm{k}$, and $\mathrm{r}$ are real-valued, commonly known constants that remain fixed across all $\mathrm{T}$ periods, and $\mathbf{d}=\left(\mathrm{d}_{1}, \mathrm{~d}_{2}, \ldots \mathrm{d}_{\mathrm{n}}\right)$ is the vector of $\mathbf{n}$ individual decisions. At the end of each period, each player is informed of the number of entrants and her payoff for the period; information about the decisions and payoffs of the other players, except of the summary statistic m, is withheld. In a symmetric version of this game (Erev \& Rapoport, 1998; Rapoport, 1995; Sundali, Rapoport, \& Seale, 1995) the entry fees were all set at zero. 
Asymmetry was induced (Rapoport, Seale, \& Winter, 1997) by charging the players differential entry fees.

The MEFC game can be viewed as the first stage in oligopoly situations preceded by a market entry stage (Gilbert \& Lieberman, 1987), and other oligopoly models with differentiated products, where price, quality parameters, or advertising expenditures are the decision variables (Selten \& Güth, 1982). It can also be interpreted as the entry stage in common auctions in which each potential bidder, to enter the auction, must incur a fixed cost representing the expense of processing information and preparing his bid (Levin \& Smith, 1996). Technically, the MEFC game is a member of a larger class of congestion games studied by Rosenthal (1973) and more recently by Milchtaich $(1996,1998)$.

\section{$\underline{\text { Equilibria }}$}

The present study considers only the symmetric case, with $h_{i}$ set at zero for all $i \in N$. To characterize the pure strategy equilibria (Rapoport, Seale, Erev, \& Sundali, 1998, hereafter RSES), two different cases must be distinguished. If $\mathrm{v} \neq \mathrm{k}+\mathrm{qr}$, for some arbitrary integer $\mathrm{q}$, there exist $\left(\begin{array}{c}n \\ m_{e}\end{array}\right)$ asymmetric pure strategy equilibria, all of them strict, each with $m_{e}$ entrants and $n-m_{e}$ non-entrants, where

$$
\mathrm{m}_{\mathrm{e}}=\left|\frac{r c+k-v}{r}\right|
$$

and $|\mathrm{x}|$ is the integral part of $\mathrm{x}$. If $\mathrm{v}=\mathrm{k}+\mathrm{qr}$, then there exist $\left(\begin{array}{c}n \\ m_{e}\end{array}\right)$ pure strategy equilibria, each with $m_{e}$ entrants and $n-m_{e}$ non-entrants. In addition, there exist $\left(\begin{array}{c}n \\ m_{e}-1\end{array}\right)$ pure strategy equilibria, each with $m_{e}-1$ entrants and $n-m_{e}+1$ non-entrants, where $m_{e}=(r c+k-v) / r$. Denoting the (symmetric) probability of entry by $p_{e}$, the symmetric mixed strategy equilibrium is given by (RSES) 


$$
\mathrm{p}_{\mathrm{e}}=\frac{r(c-1)+k-v}{r(n-1)}
$$

Comparison of Eqs. (1) and (2) shows that the number of entrants under mixed strategy equilibrium play, $n p_{e}$, is approximately the same as the number of entrants under the asymmetric pure strategy equilibrium: $n p_{\mathrm{e}} \approx \mathrm{m}_{\mathrm{e}}$. In all the games we consider below $\mid n p_{\mathrm{e}}$ $m_{e} \mid<1$. Therefore, in testing equilibrium behavior on the aggregate level, the difference between pure and mixed strategy equilibria is of little importance.

The equilibria characterized above are Pareto deficient. Expected payoff is maximized (RSES) if, given the value of $\mathrm{c}$, each player enters the market with probability $\mathrm{p}_{\mathrm{m}}$, where

$$
\mathrm{p}_{\mathrm{m}}=\frac{r(c-1)+k-v}{2 r(n-1)}
$$

Thus, $p_{m}=p_{e} / 2$. The difference in the expected payoff between randomizing entry decisions with probability $\mathrm{p}_{\mathrm{e}}$ or $\mathrm{p}_{\mathrm{m}}$ can be substantial.

\section{Behavioral Regularities.}

There are three previous experiments that are particularly relevant to the present study. The first two experiments by Sundali et al. (1995) (hereafter referred to as SRS) and by RSES, except of using the decision rather than the strategy method, are identical in all respects to the present study. These two experiments had between them five groups of $n=20$ subjects each (three groups with the same game parameters in Experiment 2 of SRS, and two additional groups with different game parameters in the RSES study) who played the MEFC game for $T==100$ periods. In each case, ten different values of $c$ were presented to the subjects, one on each period. These 10 values were randomized independently within each block of 10 periods for a total of 100 periods. As a result, the members of each group observed the same value of $c$ exactly 10 times during the course of the experiment (with 10 periods, on the average, between any two presentations of the same game) but in a different random order within each block. The values of $\mathrm{k}, \mathrm{v}$, and $\mathrm{r}$ were fixed across all 100 periods. 
The subjects in each group were given an endowment, the same for all players within the same group, and their cumulative payoff in the 100 periods was added or subtracted from the endowment to determine their take-home payment. Information about the number of entrants was provided at the end of each period.

The five groups in these two different experiments differed from one another in the value of $v$ (staying out payoff), the initial endowment, and the set $C=\{c\}$ of the 10 values of $\mathrm{c}$ that were randomly sampled and presented on each block. The particular values of these parameters and the reasons for choosing them will be described in Section 3 below. The major findings were 1) a remarkable coordination with convergence to equilibrium on the aggregate level (these results are presented and discussed in Section 4); 2) considerable individual differences in frequency of entry that did not seem to diminish with experience; and 3) failure of the equilibrium solution to account for the behavior of individual subjects.

These findings shifted the emphasis in a subsequent study by Rapoport et al. (1997) (hereafter RSW) to the dynamics of play and the evolution of coordination. Their study included two groups of asymmetric players $(n=20$ in each case $)$, who differed from one another in their entry fee. Each player was informed of his entry fee and the number of players with other entry fees (five types altogether). Similarly to the study by RSES, RSW also included 100 periods of play and ten values of the market capacity $c$ that were sampled randomly and without replacement form the set $\mathrm{C}=\{\mathrm{c}\}$ separately on each of ten blocks of periods. The values of $\mathrm{k}, \mathrm{v}$, and $\mathrm{r}$ were fixed for all 100 periods. A subject in their experiment was said to use a cutoff policy with a threshold $\mathrm{c}^{*}$ in a given block of ten periods, if all his ten decisions on that block could be accounted for perfectly by the decision rule of the form "enter if and only if $c \geq c^{*}$ ". The value of $c^{*}$, inferred from the ten decisions, was allowed to change between blocks and across subjects. A major finding of their study (RSW, Table 6) 
was that the percentage of cutoff decision rules computed across the subjects in both groups increased steadily across blocks from 32.5 percent in block 1 to 80 percent in block 10 .

Based on these findings, RSW proposed and tested an adaptive learning model postulating that 1) each subject $i$ starts the experiment with a cutoff decision rule with parameter $\left.c_{i, 1}{ }^{*} ; 2\right)$ the value of $c_{i, t}{ }^{*}$ varies from period $t-1$ to period $t$ as a function of the outcome of period $t-1 ; 3$ ) with experience, $c_{i, t}{ }^{*}$ converges to fixed cutoff point $c_{i}{ }^{*}$ that no longer changes as a function of previous outcomes; and 4) the converged values of $c_{i}{ }^{*}$ are distributed in the population of subjects in such a way to give rise to coordination on the equilibrium values. Although this learning model accounted successfully for many features of the data, the existence of cutoff decision rules could only be inferred from decisions. As mentioned earlier, a major purpose of the present study is to elicit these strategies, if they exist, directly by the strategy method and study their evolvement over time.

\section{Method}

Subjects. Sixty subjects participated in the experiment that lasted a single session of approximately 2 hours. The subjects were divided into three groups of 20 subjects each referred to as Conditions $+1,-6$, and +6 . The subjects were University of Arizona students, both undergraduates and graduates, who in response to advertisements posted on campus volunteered to participate in a decision making experiment with payoff contingent on performance. The subjects earned on the average $\$ 21.7$. The payoff ranges (including a $\$ 5.00$ show-up fee) were $(14.50,30.50),(9.25 .27 .00)$, and $(16.50,29.25)$ for Conditions $+1,-6$, and +6 , respectively.

Procedure. The experiment was computer controlled. Upon arrival at the computer laboratory, the 20 subjects were seated at one of 20 PC terminals. Communication between the subjects during the experiment was not possible. The subjects were handed written instructions, which they could read at their own pace with no time pressure. The major points 
of the instructions were repeated verbally by the experimenter to ensure that the instructions are common knowledge. The Appendix shows a copy of the instructions for Condition +6 .

The subjects were instructed that they would participate in a decision making experiment simulating independent decisions made by firms whether or not to enter a newly established market. They were told that the game would be repeated for 50 periods. The procedure for eliciting individual strategy profiles was very similar to the one used by Mitzkewitz and Nagel. At the beginning of each period, the same ten different values of $\mathrm{c}$ (interpreted as the potential capacities of the market) were displayed on the individual computer screens. Each subject had then to decide for each value of $\mathrm{c}$ separately whether to enter this market $(\mathrm{Y})$ or stay out of it $(\mathrm{N})$. After making their ten (binary) decisions, the subjects could change them before were asked to verify them. Once all the 20 group members entered in their vectors of decisions, a value of $\mathrm{c}$ was chosen randomly and without replacement from a set $C=\{c\}$, that differed from one condition to another (see below). The computer counted the number of entrants $m(0 \leq m \leq n)$ for that particular value of $c$ and displayed it on the individual screens. In addition, each subject was informed of her payoff for the trial. No other information about the strategy choices of the other group members or their individual payoffs was provided.

The same procedure was repeated five times for a total of five blocks of ten periods each $(T=50)$. Thus, each of the ten values of $c$ was chosen and presented exactly five times during the entire experiment. On the average, ten periods separated two successive presentations of the same market capacity value.

At the beginning of the experiment, each subject was provided with an endowment (which differed between the three conditions). Individual payoffs for each period were added (if positive) or subtracted (if negative) from the endowment. At the end of 50 rounds of play, the subjects were paid their earnings plus $\$ 5.00$ show-up fee and dismissed from the 
laboratory. The experiment used a fictitious currency called "francs" that were exchanged to US dollars at the rate of $\$ 1=4$ francs.

To aid the subjects in computing their potential gains or losses, if deciding to enter the market, a $20 \times 10 \mathrm{~m}$ by c payoff table was attached to the instructions (see Appendix). The subjects could refer to this table during the experiment. Each cell of this payoff table listed the payoff for an entrant as a function of the corresponding values of $m(1 \leq m \leq 20)$ and $c$. Design. The three experimental conditions were chosen for comparison with previous experiments that used the same payoff conditions under the decision method. The SRS study included three groups of $n=20$ subjects each who participated in Condition +1 . The RSES study included two groups of $n=20$ each (a third condition of -10 was not replicated), one participating in Condition -6 and the other in Condition +6 .

The three experimental conditions differed from one another in the payoff for staying out (v), value of the individual endowment (e), and set of market capacity values (C) as follows:

Condition $+1: \mathrm{v}=+1, \mathrm{e}=20, \quad \mathrm{C}=\{1,3,5,7,9,11,13,15,17,19\}$

Condition $+6: \mathrm{v}=+6, \mathrm{e}=-230, \quad \mathrm{C}=\{4,6,8,10,11,12,14,16,18,20\}$

Condition $-6: \mathrm{v}=-6, \mathrm{e}=370, \quad \mathrm{C}=\{1,3,5,7,8,9,10,12,14,16\}$

The endowments for each condition were chosen to equate the total earnings (excluding the show-up fee) across the three conditions for subjects who decided never to enter on any value of $\mathrm{c}$ for all 50 rounds of play. A subject who decided never to enter could, therefore, guarantee herself a final payoff of 70 francs $(\$ 17.5)$, as e $+50 \mathrm{v}=70$ in each of the three conditions.

Although the differences between the three conditions are formally rather trivial, phenomenologically they are quite substantial. When $\mathrm{v}<\mathrm{k}(\mathrm{k}=1$ and $\mathrm{r}=2$ in all three conditions), staying out no longer guarantees a positive payoff. Each player faces a decision 
between staying out and losing a certain amount $\mathrm{v}$ with certainty, or entering a market where it is likely--for any value of c--that the number of entrants will exceed the market capacity. Thus, it is quite likely that either decision will result in a negative payoff. Hence, the substantial positive endowment $(\$ 92.5(1)$. Subjects in this condition typically see their capital evaporating, and they struggle to slow down the process. When $\mathrm{v}>\mathrm{k}$, staying out guarantees a positive gain. However, because it is likely that the number of entrants will fall short of the market capacity, the tension in this case is between receiving a certain positive gain with certainty or receiving an uncertain payoff whose expected payoff is likely to be positive. Hence, the substantial negative endowment (\$-57 5). Subjects in this condition start the experiment by owing money and then try to get out of their debt as quickly as possible. Cognitively. these are very different processes which may have strong effects on coordination and learning. Condition +1 , where $\mathrm{v}=\mathrm{k}$, is intermediate between Conditions -6 and +6 .

\section{Results}

We have organized the data analysis to address four issues. The first issue concerns coordination. The question we ask is whether players can achieve coordination under the strategy method, and if they can. whether they coordinate on the Pareto deficient equilibrium solution or deviate from it, by lowering their frequency of entry in the direction of maximizing group (and individual) payoff. The second issue concerns the comparison of the decision and strategy methods. The null hypothesis we set to test is that the two methods yield the same results. We next turn to the third issue, namely, the study of individual strategies. We test the null hypothesis--based on the findings of RSW-that players use cutoff decision rules from the outset, with individual cutoff points that change across rounds of play and gradually converge to different fixed cutoff points. The fourth and final issue concerns the dynamics of play, in particular the changes in the individual strategy profiles over time. 


\section{$\underline{\text { Coordination }}$}

Table 1 presents the mean frequencies of entry per period for Condition +1 . The top panel presents the results of the present study. The five rows correspond to the five blocks of ten periods each, and the ten columns to the ten values of $c$. The values of $c$ are presented in an ascending order, not in the actual order of their presentation that was varied randomly from block to block. Recall that each subject made a total of 500 decisions ( 50 periods by 10 values of c) for a total of 10,000 decisions for the group. Each cell in the top panel presents the mean of 200 decisions ( 20 subjects by 10 periods). For example, across the ten periods in Block 1 the subjects in Condition +1 made a total of 37 entry decisions on $\mathrm{c}=1$ and 57 on $\mathrm{c}$ $=3$, resulting in mean number of entries per period of 3.7 and 5.7 , respectively.

The lower panel in Table 1 presents similar results averaged across the three groups of $n=20$ subjects each, who played the same market entry game under the decision method. For comparison purposes, only the results of Blocks 1 through 5 are presented. The coordination improved considerably in Blocks 6 to 10 (periods 51 - 100); see SRS (1995) for details.

Tables 2 and 3 present the mean frequencies of entry per period for Conditions +6 and -6 . The top panel of each table is organized exactly as Table 1. The lower panels present frequencies of entry from the two corresponding conditions in RSES. The frequencies in each panel are for a single group only (rather than averaged across three groups as in Table 1). The bottom row of each panel in each of the three tables presents the expected number of entrants under mixed strategy equilibrium play.

--Insert Tables 1, 2, and 3 about here-

The frequencies of entry in Condition +1 of the present study were subjected to a $5 \times$ 10 block by $\mathrm{c}$ value ANOVA with repeated measures on both factors $(n=20$ in each cell). As expected, the main effect due to market capacity was highly significant $\left(\mathrm{F}_{9,48}=26.2, \mathrm{p}<\right.$ 0.01). The other main effect due to block was not significant $(\mathrm{F}<1)$. However, the two-way 
interaction effect was significant $\left(\mathrm{F}_{36.48}=1.78, \mathrm{p}<0.01\right)$. Inspection of Table 1 shows that the interaction is mainly due to the lowest values of $\mathrm{c}(\mathrm{c}=1, \mathrm{c}=3$, and to a lesser extend $\mathrm{c}=$ 5 ), where the frequencies generally decrease over blocks. and the highest values of $\mathrm{c}(\mathrm{c}=17$ and $c=19$ ), where the frequencies increase over blocks. In all five cases, the entry frequencies move in the direction of the equilibrium solution. By Block 5 the mean frequencies of entry increase monotonically over the entire range of the ten c values, indicating a high degree of coordination.

Similar ANOVA tests were conducted separately for the frequencies of entry in Conditions +6 and -6 . In both cases, the main effect due to market capacity was significant $\left(F_{9,48}=30.9, p<0.01\right.$, and $F_{9,48}=27.1$, for Conditions +6 and -6 , respectively $)$. Neither the main effect due to block $\left(\mathrm{F}_{4,48}=0.73\right.$ and $\mathrm{F}_{4,48}=1.49$ for Conditions +6 and -6 , respectively $)$ nor the interaction effect $\left(\mathrm{F}_{36,48}=1.26\right.$ and $\left.\mathrm{F}_{36,48}=1.16\right)$ were significant. Table 2 shows that, similarly to Table 1 , the mean frequency of entry for $c=4$ decreased across blocks and the one for $\mathrm{c}=20$ increased slightly. These effects, however, are not significant. We observe no such trends across blocks in Condition -6 (Table 3 ).

Comparison of the mean frequency of entry across blocks (shown in boldface) with the expected number of entrants under equilibrium play (bottom row) shows that the equilibrium solution organizes the aggregate results of all three conditions remarkably well. There are very few significant differences between observed and predicted expected number of entrants, and they mostly occur for extreme c values. The descriptive power of the equilibrium solution is, in fact, much better than shown in Tables 1, 2, and 3 . In order to compare the results across the two different procedures--the decision and strategy methodsthe three tables present the mean frequency of entry. Whereas the mean is the appropriate statistic to describe the central tendency for intermediate values of $\mathrm{c}$, it is inappropriate when the expected number of entrants is close to either 0 or 20 . This is so because the distributions 
of number of entries in these extreme cases are highly skewed. In these cases, the median rather than the mean is the appropriate statistical measure.

To illustrate this point, we computed the median number of entries for $\mathrm{c}=1$ in Condition +1 . For all five blocks, the median number of entries was, in fact, zero. Indeed, 10 of the 20 subjects in this condition never entered on $\mathrm{c}=1$ in all 50 periods, and 5 more subjects entered at most on 4 periods. A similar analysis for $c=3$ in Condition +1 shows that the median number of entries for Blocks $1,2,3,4$. and 5 was $1,0,0,0$, and 0 , respectively. Of the 20 subjects, 8 never entered on $c=3$, and 4 more subjects entered at most on 5 out of 50 periods. The median number of entries for $\mathrm{c}=19$ in Condition +1 was $8,9,9,10$, and 10 in Blocks 1, 2, 3, 4, and 5, respectively. Eleven of the 20 subjects entered on 46 or more periods out of 50 , compared to the mixed strategy equilibrium prediction of $50 \times \mathrm{p}_{\mathrm{e}}(\mathrm{c}=19)=$ $50(18 / 19)=47.37$

Similar results obtain for the other two conditions. Tables 2 and 3 show that the mean number of entries increases monotonically in $\mathrm{c}$ (with a minor exception for $\mathrm{c}=10$ in Condition -6$)$. When the means are replaced by medians for extreme values of $c(c=4$ in Condition +6 and $c=19$ in Conditions +6 and -6 ), the differences between observed and predicted number of entries decrease.

Figures 1, 2, and 3 display the running mean (in steps of 10 periods) of the frequencies of entry for all ten values of $\mathrm{c}$ in Conditions $+1,+6$, and -6 , respectively. Figure 1 shows that the running means in Condition +1 diverge and approach the expected number of entries under mixed strategy equilibrium play. It would seem that convergence to the equilibrium values has not been reached by period 50 , particularly for the extreme values of $\mathrm{c}$ $=1$ and $\mathrm{c}=19$. Figure 2 displays more rapid convergence. But here, too, the running mean for $c=1$ continues to decrease over time. By period 50 the means increase monotonically in the ten values of $\mathrm{c}$. The only discordant trend is for $\mathrm{c}=12$, where the running mean decreases 
steadily after approximately 20 periods. Figure 3 shows that fastest convergence was reached in Condition -6 . With minor exceptions for $c=9$ and $c=17$, the means on period 50 increase monotonically in the values of $\mathrm{c}$.

--Insert Figures 1, 2, and 3 about here-

Two summary statistics are particularly useful for assessing the descriptive power of the equilibrium solution across the ten market capacity values. Both were computed for each period separately. The first is the product moment correlation (based on 10 pairs of observations) between the observed frequencies of entry $f(c)$ and the values of $c$. The second is the mean square deviation (MSD) score

$$
\mathrm{MSD}=\frac{1}{10} \sum_{c \in C} \sqrt{\left[f(c)-n p_{c}(c)\right]^{2}}
$$

where $f(c)$ is the observed frequency of entry (summed across all the group members) for some value of $\mathrm{c}, n \mathrm{n}_{\mathrm{c}}(\mathrm{c})$ is the expected number of entries under mixed strategy equilibrium play for the same value of $\mathrm{c}$, and summation is across all ten values of $\mathrm{c}$. The three panels of Fig. 4 exhibit the running mean (computed across the last 10 periods) of these two summary statistics for all three conditions. The correlations are seen to converge very rapidly to 0.97 , 0.92 , and 0.95 for Conditions $+1,+6$, and -6 , respectively. They are of the same order of magnitude as the ones observed in all previous studies that used the decision method. The MSD scores for Condition +1 (top panel) decrease steadily over time in correspondence with the trends observed in Fig. 1. In contrast, the MSID scores for the other two conditions (middle and bottom panels) do not exhibit any systematic trend.

--Insert Fig. 4 about here--

\section{Comparison of the Strategy and Decision Methods}

Comparison of the frequency data collected under the two methods yields very similar results. Under both methods coordination improves across blocks. With some exceptions, by the fifth block the entry frequencies in both conditions increase monotonically in the market 
capacity values. Tables 1,2 , and 3 indicate that, with possible exceptions at the extreme values of $c$, the mean number of entries do not differ significantly from one method to another. To compare the two methods to each other, we computed for each subject the mean number of entries for each value of $c$ separately. For the strategy method, this statistic is based on 50 observations, and for the decision method on 5 observations only. This statistic assumes the value of 0 , if a subject never entered on this particular value of $c$, and 1 , if he always entered. We then used the two-sided t-test to compare to each other the two methods for each value of $c$ separately $\left(n_{1}=20\right.$ for the strategy method and $n_{2}=60$ for the decision method in Condition +1 , and $n_{1}=n_{2}=20$ for each of the other two conditions). Of the $30 \mathrm{t}$ tests, only one was significant for $\mathrm{c}=19$ in Condition $+1\left(\mathrm{t}_{78}=0.036, \mathrm{p}<0.05\right)$. Table 1 shows that on this extreme value of $\mathrm{c}$, for which the equilibrium number of entries is 18.4 , fewer subjects entered on the average under the strategy than decision method.

\section{$\underline{\text { Individual Strategies }}$}

How do the players in the MEFC game coordinate their actions? RSW proposed an elaborate but sensible answer to this question in terms of cutoff decision rules, with cutoff values that differ initially from player to player (possibly reflecting different previous experiences with similar coordination tasks) and gradually converge over time to fixed values that are distributed in the subject population in a way that achieves coordination success. Indirect evidence for this hypothesis was provided by their analysis of the cutoff values that they inferred from the subjects' decisions in each block of ten periods. An adaptive learning model that incorporates this assumption accounts remarkably well for a wide range of statistics. A major purpose of the present study was to elicit these decision rules directly through the strategy method and study changes in the cutoff values over time. In sharp contrast to our expectations, the results of the present study provide no support for the cutoff decision rule hypothesis. We observe diverse strategy profiles that in general are difficult to 
interpret and seem to defy classification. To fully appreciate the diversity of the strategy profiles and their evolvement over time, Figs. 5, 6, and 7 display the complete strategy profiles for all 50 periods for each of the 60 subjects. Because only 10 complete profiles can be fitted on a single page, each figure is divided into two parts. The individual profiles of Subjects $1-20($ Condition +1$), 21-40($ Condition +6$)$, and $41-60($ Condition -6$)$ are exhibited in Figs. 5, 6, and 7, respectively.

--Insert Figs. 5, 6, and 7 around here-

Evidence in support of cutoff decision rules, possibly with a few errors, can be found in the profiles of Subjects 5, 6, and 17 in Condition +1 ; Subjects 21, 22, 39, and 40 in Condition +6 ; and Subject 43 in Condition -6 . Except of Subject 5, who used the same cutoff value consistently across all 50 periods, the cutoff values of the other seven subjects often changed over time (see, e.g., the profiles of Subjects 17 and 40). There are a few more subjects who used a cutoff decision rule only in the second half of the experiment. These include Subjects $1,2,8,13,15$, and 18 in Condition +1 ; Subject 38 in Condition +6 ; and Subjects 42, 49 (who never entered after period 16), and 57 in Condition -6 . The profiles of the other subjects do not show any consistent patterns; see e.g., Subject 51 whose profile looks like an apartment house in the Bronx at 11 p.m., Subjects 24, 45, and 50, who avoided intermediate values of $\mathrm{c}$, or Subject 3 who alternated between entering or staying out on all ten values of $c$. The non-monotonic profiles we observe are not unlike the ones reported by Selten and Buchta in their study of the sealed bid first price auction.

The strategy method does not allow for randomization within a period. However, mixed strategy equilibrium play can be supported on the individual level by subjects who randomize -in one form or another-across the 50 periods. The hypothesis that the 50 individual decisions for some value of $\mathrm{c}$ form a binary sequence with a fixed probability is clearly unrealistic. A weaker implication of some attempt on the part of the subject for 
randomization is that the total frequencies of entry across the 50 periods increase in the value of c. Whereas we find strong support for this hypothesis on the aggregate level (see above), we find no support for it on the individual level. The only possible exception is Subject 19. Although subjects may not use cutoff decision rules across all 50 periods, they may use them occasionally. We counted the number of cutoff decision rules across subjects for each period separately. Figure 8 displays the running mean (in steps of 10) of these frequencies. The figure shows that the number of cutoff decision rules per period more than doubled from 7.3 in period 1 to 16.0 in period 50 in Condition +1 . In contrast, no such trend is observed for the other two conditions, where the number of cutoff decision rules stays between 10 and 11 for most of the periods.

$$
\text { --Insert Fig. } 8 \text { about here-- }
$$

\section{Dynamics of Play}

If coordination is achieved and aggregate behavior converges to equilibrium, there is no benefit for any subject to unilaterally change her strategy profile over time. A subject may do so if she attempts to randomize her decisions for the same value of $\mathrm{c}$ across periods; however, our analysis of the individual strategy profiles in Figs. $5-7$ does not support this hypothesis. The changes in strategy profiles are particularly striking in Conditions +6 and -6 . where coordination was reached quite early in the game (Tables 2 and 3), the MDS scores stayed more or less constant across time (Fig. 4), and the number of cutoff decision rules was also more or less stable across all 50 periods of play (Fig. 8).

We computed for each period separately the total number of switches across the 20 subjects. Because a strategy profile includes ten binary choices, the minimum number of switches per subject from period t to period $t+1$ is 0 and the maximum is 10 , for a total maximum number of switches per subject of 490 and per period of 200 . Figure 9 (upper function in each panel) displays the runuing mean of the number of switches per period over 
time. In all three groups, the running mean of total number of switches decreases across periods. For Condition +1 , the function decreases steadily from 77 on period 1 to 22.6 on the last 10 periods. In the other two conditions, the running mean decreases steadily on the first $10-15$ periods, and then stabilizes around 35 . Figures $5-7$ show that the individual differences in total number of switches are considerable, from a minimum of 9 for Subject 5 (who switched on 9 of his 10 decisions on the last period only) to 219 for Subject 9 (both subjects are members of Condition +1 ).

--Insert Fig. 9 about here--

Because subjects were only told the number of entrants for the particular value of $\mathrm{c}$ realized on period $t$, one would expect that most of the switches from period t to $t+1$ would occur at or "in the neighborhood" of that particular value. To test this hypothesis, we counted for each subject the number of switches on the values of $c, c+1$, and $c-1$. If $c$ assumed its lowest value on period t. only the number of switches for $c$ and $c+1$ was counted. And if $c$ assumed its highest value, only the number of switches for $\mathrm{c}$ and $\mathrm{c}-1$ was counted. The expected number of switches per subject "in the neighborhood" of c so defined is 137.2 [(0.8 $\times 3+0.2 \times 2) \times 49=137.2]$. Under the null hypothesis that this expected frequency is not different from the expected frequencies for other values of $\mathrm{c}$, the proportion of switches "in the neighborhood of $\mathrm{c}^{\prime \prime}$ is $137.2 / 490=0.28$. The evidence does not reject this null hypothesis: the expected proportion of switches "in the neighborhood" of $\mathrm{c}$ was $32.23,35.90$, and 33.75 for Conditions $+1,+6$, and -6 , respectively $\left(t_{19}<1.4\right.$ in each case). The running means of these proportions across periods are displayed in the three panels of Fig. 9.

\section{Discussion}

Players who participate in the MEFC game converge to the equilibrium solution. They do so despite the fact that the market capacity values differ across periods, and knowledge about the strategy profiles of others is not provided. Rather, under both the 
decision and strategy methods, players only learn the number of entrants for a particular market capacity value realized on the current period. With no record of these values, it is difficult for the players to recall them approximately ten periods later when the same value of $\mathrm{c}$ is presented for the next time. Players converge to the equilibrium solution despite the fact that it is Pareto deficient. For example, if $\mathrm{c}=17$ in Condition +1 , the expected payoff under mixed strategy equilibrium play is $v=1$. But if each subject enters with probability $p_{m}$ rather than $p_{e}\left(p_{m}=0.421\right.$ in this case), the expected payoff increases sharply from 1 to 7.74 . There is much money to be made in the MEFC game, particularly for relatively large values of $\mathrm{c}$. However, we observe no attempt to exploit this opportunity by subjects lowering their frequency of entry. These findings are very robust. We have replicated them with different payoff conditions and either symmetric or asymmetric players under the decision method (RSES, RSW, and SRS), and with different payoff conditions in the present study.

How do heterogenous players, who differ from one another so markedly in their total frequency of entry and, in particular, in their strategy profiles achieve this coordination? There is indirect evidence gathered under the decision method by RSW that subjects converge to using cutoff decision rules with cutoff values that differ across subjects. In contrast, under the strategy method the direct evidence for cutoff decision rules is limited to a small minority of the subjects. There is a steady increase in the use of cutoff decision rules between rather than within subjects (Fig. 8), but it is mostly found in one of the three conditions. Similarly, the steady decrease in period-to-period frequency of switches between strategy profiles (Fig. 9) is also mostly restricted to Condition +1 . The explanation of dynamics of play and the diversity of individual strategy profiles in the present study is a challenge to any adaptive learning model that is not restricted to aggregate behavior, but also attempts to account for individual behavior. 
We conclude with an observation about the strategy method. As implemented in the present study and all the studies that preceded it, the strategy method does not allow to examine randomization within a period. A variant of the strategy method that permits direct observation of mixed strategies requires the subject to specify a probability of entry for each value of $c$. This is a generalization of the method used in the present study with probability values no longer restricted to either 0 or 1 . For example, if the subject wishes to enter on $\mathrm{c}=$ 7 with probability 0.4 , then entry $(d=1)$ is chosen by the computer (or some other random device) with probability 0.4 and non-entry $(d=0)$ with the complementary probability. Once individual strategy profiles are thus determined, the number of entrants for some value of $c$ is computed by adding the profiles across subjects.

Although we did not use this variant of the strategy method in our study, at the end of the experiment we administered a questionnaire with the following question: "Supposing you were to participate in the same experiment for 50 additional periods. Please specify the number of times, out of 50 , that you would enter on each of the ten values of $c^{\prime \prime}$. The same ten values of $\mathrm{c}$ observed in the experiment were presented, and each subject $\mathrm{i}$ entered ten values denoted by $m_{i}(c)$, where $m_{i}(c)=0,1, \ldots, 50$. Because no payoff was contingent on these responses, the answers to this question should be interpreted with caution.

Table 4 summarizes the results. For each condition separately, it presents the ten values of $\mathrm{c}$, the corresponding mean number of entries $\mathrm{m}(\mathrm{c})\left(\mathrm{m}(\mathrm{c})=\sum_{i=1}^{n} m_{i}(c)\right)$, the associated standard deviations, and the expected number of entrants (in boldface) under mixed strategy equilibrium play. For each of the three conditions, the values of $\mathrm{m}(\mathrm{c})$ are seen to increase monotonically in the values of $\mathrm{c}$. The product-moment correlations between $\mathrm{c}$ and $\mathrm{m}(\mathrm{c})$ are $0.98,0.97$, and 0.97 for Conditions $+1,+6$, and -6 , respectively. They are of the same order of magnitude as the ones reported in Fig. 4. Some minor deviations from the expected frequencies of entry can be detected: subjects reported lower frequencies of entry for 
relatively small values of $\mathrm{c}$ and higher values than expected for intermediate values of $\mathrm{c}$. However, because of the large standard deviations (which indicate a high degree of heterogeneity of the same order of magnitude observed in the strategy profiles), the differences hetween observed and expected means are not significant.

Of the 60 reported individual vectors of strategies, 8 were of the cutoff type, namely $(0,0, \ldots, 50,50)$. This is the same frequency that we reported earlier for the strategy profiles in Figs. 5, 6. and 7. However, in sharp contrast to most of the strategy profiles displayed in these three figures, 40 of the 60 subjects (including the 8 just mentioned above) reported response vectors in which all ten values of $\mathrm{m}_{\mathrm{i}}(\mathrm{c})$ are non-decreasing in $\mathrm{c}$. These results suggest that although the major finding of coordination on the aggregate level is robust, individual behavior is highly susceptible to the details of the experimental procedure and the method used for eliciting strategies or decisions.

--Insert Table 4 about here-- 


\section{References}

Axelrod, R. (1984). The Evolution of Cooperation. New York: Basic Books.

Daniel, T. E., Rapoport, A., and Seale, D. A. (1998). Strategic play and adaptive learning in the sealed-bid bargaining mechanism. Journal of Mathematical Psychology, 42 , $133-166$.

Erev, I., \& Rapoport, A. (1998). Coordination, "magic", and reinforcement learning in a market entry game. Games and Economic Behavior, 23, $145-176$.

Fader, P. S. and Hauser, R. (1988). Implicit coalitions in a generalized Prisoner's Dilemma. Journal of Conflict Resolution, $\underline{32,} 553$ - 582.

Gilbert, R. and Lieberman. M. (1987). Investment and coordination in oligopolistic industries. Rand Journal of Economics. 18, 17 - 39.

Levin, D. and Smith, J.L. (1996). Entry coordination in auctions: An experimental investigation. Ohio State University, Unpublished manuscript.

Linhart, P. B., Radner, R., and Satterthwaite. M. A. (1989). Introduction: Symposium on noncooperative bargaining. Journal of Economic Theory, $\underline{48}, 1-17$.

Linhart, P. B. , Radner, R., and Schotter, A. (1990). Behavior and efficiency in the sealed-bid mechanism. C. V. Starr Center for Applied Economics, Report No. 90-51.

Milchtaich, I. (1996). Congestion games with player-specific payoff functions. Games and Economic Behavior, 13, $111-124$.

Milchtaich. I. (1998). Crowding games are sequentially solvable. International Journal of Game Theory, 27, $501-509$.

Mitzkewitz, M. and Nagel, R. (1993). Experimental results on ultimatum games with incomplete information. International Journal of Game Theory, 22, 171 - 198.

Radner, R. and Schotter, A. (1989). The sealed-bid mechanism: An experimental study. Journal of Economic Theory, $\underline{48}, 179-220$. 
Rapoport, A. (1995). Individual strategies in a market entry game. Group Decision and Negotiation, 4 , $117-133$.

Rapoport, A., Daniel, T. E., and Seale, D. A. (1999). Reinforcement-based adaptive learning in asymmetric two-person bargaining with incomplete information. Experimental Economics, forthcoming.

Rapoport, A. and Fuller, M. (1995). Bidding strategies in a bilateral monopoly with two-sided incomplete information. Journal of Mathematical Psychology, $\underline{39}, 179-196$.

Rapoport, A., Seale, D. A., Erev, I., and Sundali, J. A. (1998). Equilibrium play in large group market entry games. Management Science, 44, $129-141$.

Rapoport, A., Seale, D. A., and Winter, E. (1997). Coordination and learning behavior in large groups with asymmetric players. Hong Kong University of Science and Technology, Department of Marketing. Working Paper 97.098.

Rosenthal, R. W. (1973). A class of game possessing pure-strategy Nash equilibria. International Journal of Game Theory, 2, $65-67$.

Roth. A. E. (1995). Bargaining experiments. In J. H. Kagel and A. E. Roth (Eds.), Handbook of Experimental Economics. Princeton: Princeton University Press, pp. 253 - 348. Selten, R. (1967). Die strategiemethode zur erforschung des eingeschränkt rationalen verhaltens im rahmen eines oligopolexpriments. In H. Sauermann (Ed.), Contributions to Experimental Economics, Vol. 1. Tübingen: J. C. B. Mohr, pp 136-168.

Selten, R. and Buchta, J. (1999). Experimental sealed bid first price auctions with directly observed bid functions. In D. V. Budescu, I. Erev, and R. Zwick (Eds.), Human Behavior and Games: Essays in Honor of Amnon Rapoport. Mahwah, NJ: Erlbaum, pp. 79 102. 
Selten, R. and Güth, W. (1982). Equilibrium point selection in a class of market entry games. In M. Diestler, E. Fürst, and G. Schwadiauer (Eds.), Games, Economic Dynamics, and Time Series Analysis. Wien-Würzburg: Physica-Verlag, pp. $101-116$.

Selten, R, Mitzkewitz. M., and Uhlich, G. R. (1997). Duopoly strategies programmed by experienced players. Econometrica, $\underline{65}, 517-555$.

Sundali, J. A., Rapoport, A., and Seale, D A. (1995). Coordination in market entry games with symmetric players. Organizational Behavior and Human Decision Processes, $\underline{64}$. $203-218$. 


\section{Acknowledgement}

This research has been supported in part by NSF Grant No. SBR-9512724 on market entry games, and in part by a grant from the Hong Kong Research Grants Council (Project No. CA98/99.BM01). We wish to thank Rami Zwick for helpful suggestions. The second author wishes to thank the Marketing Department at the Hong Kong University of Science and Technology for its support and hospitality. 
Table 1

Mean Frequency of Entry per Period by Block and Market Capacity Value: Condition +1

Strategy Method: (present study)

Market Capacity Value (c)

\begin{tabular}{|c|c|c|c|c|c|c|c|c|c|c|c|}
\hline Block & 1 & 3 & 5 & 7 & 9 & 11 & 13 & 15 & 17 & 19 & Total \\
\hline 1 & 3.7 & 5.7 & 6.2 & 7.0 & 7.7 & 10.2 & 11.0 & 12.2 & 12.7 & 13.9 & 90.3 \\
\hline 2 & 26 & 3.9 & 5.7 & 6.2 & 8.4 & 11.8 & 12.5 & 13.8 & 15.0 & 16.0 & 95.9 \\
\hline 3 & $1 \overline{3}$ & 3.5 & 4.1 & 6.7 & 9.0 & 11.5 & 12.4 & 13.8 & 15.5 & 16.1 & 93.9 \\
\hline 4 & 11 & 3.5 & 5.3 & 7.8 & 6.7 & 10.1 & 13.0 & 13.6 & 16.8 & 17.4 & 95.3 \\
\hline 5 & 10 & 3.9 & 4.4 & 6.1 & 6.4 & 10.8 & 13.8 & 14.1 & 15.6 & 16.6 & 92.7 \\
\hline Mean & 1.9 & 4.1 & 5.1 & 6.8 & 7.6 & 10.9 & 12.5 & 13.5 & 15.1 & 16.0 & 93.6 \\
\hline$\overline{\mathrm{SD}}$ & 1.18 & 0.92 & 0.88 & 0.69 & 1.10 & 0.76 & 1.02 & 0.75 & 1.51 & 1.30 & \\
\hline Equil. & () & 2.11 & 4.21 & 6.32 & 8.42 & 10.53 & 12.63 & 14.74 & 16.84 & 18.95 & 94.75 \\
\hline
\end{tabular}

Decision Method: (SRS, 1995)

Market Capacity Value (c)

\begin{tabular}{|c|c|c|c|c|c|c|c|c|c|c|c|}
\hline Block & 1 & 3 & 5 & 7 & 9 & 11 & 13 & 15 & 17 & 19 & Total \\
\hline 1 & 1.33 & 5.67 & 9.67 & 6.67 & 3.67 & 14.00 & 11.33 & 11.33 & 16.00 & 18.00 & 97.67 \\
\hline 2 & 0.67 & 4.00 & 5.00 & 7.00 & 11.33 & 11.33 & 11.67 & 15.00 & 16.67 & 18.33 & 101.00 \\
\hline 3 & 1.33 & 3.00 & 4.00 & 8.67 & 10.00 & 9.33 & 13.67 & 14.00 & 16.00 & 18.67 & 98.67 \\
\hline 4 & 1.33 & 3.00 & 5.67 & 7.00 & 10.33 & 11.00 & 13.67 & 12.67 & 16.00 & 18.33 & 99.00 \\
\hline 5 & 0.33 & 2.33 & 4.33 & 6.00 & 9.00 & 10.67 & 11.33 & 16.33 & 16.67 & 18.67 & 95.67 \\
\hline Mean & $\mathbf{1 . 0 0}$ & $\mathbf{3 . 6 0}$ & $\mathbf{5 . 7 3}$ & $\mathbf{7 . 0 7}$ & $\mathbf{8 . 8 6}$ & 11.27 & $\mathbf{1 2 . 3 3}$ & $\mathbf{1 3 . 8 7}$ & $\mathbf{1 6 . 2 7}$ & $\mathbf{1 8 . 4 0}$ & $\mathbf{9 8 . 4 0}$ \\
\hline SD & 0.47 & 1.30 & 2.29 & 0.98 & 3.02 & 1.71 & 1.22 & 1.95 & 0.36 & 0.28 & \\
\hline Equil. & $\mathbf{0}$ & $\mathbf{2 . 1 1}$ & $\mathbf{4 . 2 1}$ & $\mathbf{6 . 3 2}$ & $\mathbf{8 . 4 2}$ & $\mathbf{1 0 . 5 3}$ & $\mathbf{1 2 . 6 3}$ & $\mathbf{1 4 . 7 4}$ & $\mathbf{1 6 . 8 4}$ & $\mathbf{1 8 . 9 5}$ & $\mathbf{9 4 . 7 5}$ \\
\hline
\end{tabular}


Table 2

Mean Frequency of Entry per Period by Block and Market Capacity Value: Condition +6

Strategy Method: (present study)

Market Capacity Value (c)

\begin{tabular}{|c|c|c|c|c|c|c|c|c|c|c|c|}
\hline Block & 4 & 6 & 8 & 10 & 11 & 12 & 14 & 16 & 18 & 20 & Total \\
\hline 1 & 3.5 & 3.2 & 5.8 & 6.2 & 7.9 & 10.4 & 11.7 & 11.6 & 13.5 & 14.9 & 88.7 \\
\hline 2 & 1.0 & 2.9 & 5.2 & 6.8 & 9.5 & 12.0 & 13.8 & 11.4 & 12.5 & 14.7 & 89.8 \\
\hline 3 & 1.7 & 3.7 & 4.0 & 6.8 & 8.4 & 8.7 & 11.0 & 12.9 & 14.3 & 15.2 & 86.7 \\
\hline 4 & 1.2 & 2.6 & 4.1 & 5.9 & 5.3 & 7.9 & 11.0 & 12.3 & 13.9 & 15.1 & 79.3 \\
\hline 5 & 0.3 & 3.0 & 4.7 & 6.3 & 8.4 & 6.7 & 10.9 & 13.3 & 12.5 & 15.7 & 81.8 \\
\hline Mean & $\mathbf{1 . 5}$ & $\mathbf{3 . 1}$ & $\mathbf{4 . 8}$ & $\mathbf{6 . 4}$ & $\mathbf{7 . 9}$ & $\mathbf{9 . 1}$ & $\mathbf{1 1 . 7}$ & $\mathbf{1 2 . 3}$ & $\mathbf{1 3 . 3}$ & $\mathbf{1 5 . 1}$ & $\mathbf{8 5 . 3}$ \\
\hline SD & 1.21 & 0.41 & 0.76 & 0.39 & 1.57 & 2.09 & 1.23 & 0.82 & 0.82 & 0.38 & \\
\hline Equil. & $\mathbf{0 . 5 3}$ & $\mathbf{2 . 6 3}$ & $\mathbf{4 . 7 9}$ & $\mathbf{6 . 8 4}$ & $\mathbf{7 . 8 9}$ & $\mathbf{8 . 9 5}$ & $\mathbf{1 1 . 0 5}$ & $\mathbf{1 3 . 1 6}$ & $\mathbf{1 5 . 2 6}$ & $\mathbf{1 7 . 3 7}$ & $\mathbf{9 1 . 6 3}$ \\
\hline
\end{tabular}

Decision Method: (RSES, 1998)

Market Capacity Value (c)

\begin{tabular}{|c|c|c|c|c|c|c|c|c|c|c|c|}
\hline Block & $\overline{4}$ & 6 & 8 & 10 & 11 & 12 & 14 & 16 & 18 & 20 & Total \\
\hline 1 & $\overline{4}$ & 5 & 6 & 4 & 9 & 11 & 10 & 14 & 16 & 15 & 93 \\
\hline 2 & 1 & 4 & 7 & 11 & 10 & 6 & 12 & 15 & 16 & 16 & $\overline{99}$ \\
\hline 3 & 1 & 3 & 7 & 10 & 6 & 9 & 10 & 11 & 11 & 18 & 86 \\
\hline 4 & 3 & 4 & 13 & 5 & 11 & 13 & 14 & 14 & 15 & 16 & 108 \\
\hline 5 & 2 & 5 & 6 & 5 & 14 & 12 & 13 & 13 & 17 & 19 & 106 \\
\hline Mean & 2.2 & 4.2 & 7.8 & 7.0 & 10.0 & 10.2 & 11.8 & 13.4 & 15.0 & 16.8 & 98.4 \\
\hline SD & 1.30 & 0.84 & 2.95 & 3.24 & 2.92 & 277 & 1.79 & 1.52 & 2.35 & 1.64 & \\
\hline Equil. & 0.53 & 2.63 & 4.79 & 6.84 & 7.89 & $8 . \overline{95}$ & 11.05 & 13.16 & 15.26 & 17.37 & 91.63 \\
\hline
\end{tabular}


Table 3

Mean Frequency of Entry per Period by Block and Market Capacity Value: Condition -6

Strategy Method: (present study)

Market Capacity Value (c)

\begin{tabular}{|c|c|c|c|c|c|c|c|c|c|c|c|}
\hline Block & 1 & 3 & 5 & 7 & 8 & 9 & 10 & 12 & 14 & 16 & Total \\
\hline 1 & 4.0 & 6.3 & 8.4 & 10.8 & 12.1 & 13.8 & 14.8 & 15.0 & 16.7 & 17.1 & 119.0 \\
\hline 2 & 5.3 & 7.6 & 7.0 & 7.6 & 12.7 & 13.7 & 12.8 & 14.9 & 16.1 & 17.3 & 115.0 \\
\hline 3 & $3 . \overline{9}$ & 8.3 & 7.0 & 9.1 & 12.3 & 12.1 & 11.1 & 14.6 & 15.6 & 17.1 & 111.1 \\
\hline 4 & $6 . \overline{0}$ & 5.0 & 7.7 & 9.5 & 10.2 & 10.6 & 11.3 & 13.2 & 14.5 & 17.0 & 105.0 \\
\hline 5 & $5 . \overline{0}$ & 5.3 & 7.8 & 10.1 & 11.4 & 11.1 & 11.1 & 13.0 & 16.6 & 16.5 & 107.9 \\
\hline Mean & $\overline{4.8}$ & 6.5 & 7.6 & 9.4 & 11.7 & 12.3 & 12.2 & 14.1 & 15.9 & 17.0 & 111.6 \\
\hline$\overline{\mathrm{SD}}$ & $0 . \overline{89}$ & 1.43 & 0.59 & 1.20 & 0.98 & 1.46 & 1.61 & 0.96 & 0.90 & 0.30 & \\
\hline Equil. & $3 . \overline{68}$ & 5.79 & 7.89 & 10.00 & 11.05 & 12.11 & 13.16 & 15.26 & 17.37 & 19.47 & 115.78 \\
\hline
\end{tabular}

Decision Method: (RSES, 1998)

Market Capacity Value (c)

\begin{tabular}{|c|c|c|c|c|c|c|c|c|c|c|c|}
\hline Block & 1 & 3 & 5 & 7 & 8 & 9 & 10 & 12 & 14 & 16 & Total \\
\hline 1 & 4 & 9 & 9 & 9 & 9 & 15 & 9 & 17 & 17 & 18 & 116 \\
\hline 2 & 6 & 9 & 4 & 14 & 10 & 15 & 15 & 13 & 12 & 20 & 118 \\
\hline 3 & 6 & 10 & 12 & 10 & 11 & 11 & 12 & 14 & 18 & 18 & 122 \\
\hline 4 & 4 & 5 & 9 & 9 & 14 & 11 & 13 & 16 & 18 & 20 & 119 \\
\hline 5 & 6 & 12 & 9 & 9 & 10 & 12 & 12 & 13 & 15 & 16 & 114 \\
\hline Mean & $\mathbf{5 . 2}$ & $\mathbf{9 . 0}$ & $\mathbf{8 . 6}$ & $\mathbf{1 0 . 2}$ & $\mathbf{1 0 . 8}$ & $\mathbf{1 2 . 8}$ & $\mathbf{1 2 . 2}$ & $\mathbf{1 4 . 6}$ & $\mathbf{1 6 . 0}$ & $\mathbf{1 8 . 4}$ & $\mathbf{1 1 7 . 8}$ \\
\hline SD & 1 & 2.55 & 2.88 & 2.17 & 1.92 & 2.05 & 2.17 & 1.82 & 2.55 & 1.67 & \\
\hline Equil. & $\mathbf{3 . 6 8}$ & $\mathbf{5 . 7 9}$ & $\mathbf{7 . 8 9}$ & $\mathbf{1 0 . 0 0}$ & $\mathbf{1 1 . 0 5}$ & $\mathbf{1 2 . 1 1}$ & $\mathbf{1 3 . 1 6}$ & $\mathbf{1 5 . 2 6}$ & $\mathbf{1 7 . 3 7}$ & $\mathbf{1 9 . 4 7}$ & $\mathbf{1 1 5 . 7 8}$ \\
\hline
\end{tabular}


Table 4

Mean Reported Number of Entries by Market Capacity Value and Condition

Condition +1

\begin{tabular}{|c|c|c|c|c|c|c|c|c|c|c|c|}
\hline $\mathrm{c}$ & 1 & 3 & 5 & 7 & 9 & 11 & 13 & 15 & 17 & 19 & Total \\
\hline $\mathrm{m}(\mathrm{c})$ & 0.72 & 2.06 & 2.20 & 4.32 & 6.62 & 11.68 & 14.82 & 15.92 & 18.14 & 18.56 & 95.04 \\
\hline $\mathrm{SD}(\mathrm{c})$ & 4.93 & 11.78 & 11.24 & 14.66 & 19.12 & 19.23 & 15.50 & 16.02 & 10.97 & 10.62 & \\
\hline $\mathrm{np}_{\mathrm{e}}$ & $\mathbf{0}$ & $\mathbf{2 . 1 1}$ & $\mathbf{4 . 2 1}$ & $\mathbf{6 . 3 2}$ & $\mathbf{8 . 4 2}$ & $\mathbf{1 0 . 5 3}$ & $\mathbf{1 2 . 6 3}$ & $\mathbf{1 4 . 7 4}$ & $\mathbf{1 6 . 8 4}$ & $\mathbf{1 8 . 9 5}$ & $\mathbf{9 4 . 7 5}$ \\
\hline
\end{tabular}

\section{Condition +6}

\begin{tabular}{|c|c|c|c|c|c|c|c|c|c|c|c|}
\hline $\mathrm{c}$ & 4 & 6 & 8 & 10 & 11 & 12 & 14 & 16 & 18 & 20 & Total \\
\hline $\mathrm{m}(\mathrm{c})$ & 0.62 & 1.32 & 2.84 & 6.18 & 7.80 & 10.50 & 13.22 & 14.68 & 14.82 & 16.74 & 88.72 \\
\hline $\mathrm{SD}(\mathrm{c})$ & 3.14 & 5.34 & 7.93 & 12.53 & 12.54 & 11.95 & 14.14 & 14.67 & 15.01 & 12.87 & \\
\hline $\mathrm{np}_{\mathrm{e}}$ & $\mathbf{0 . 5 3}$ & $\mathbf{2 . 6 3}$ & $\mathbf{4 . 7 9}$ & $\mathbf{6 . 8 4}$ & $\mathbf{7 . 8 9}$ & $\mathbf{8 . 9 5}$ & $\mathbf{1 1 . 0 5}$ & $\mathbf{1 3 . 1 6}$ & $\mathbf{1 5 . 2 6}$ & $\mathbf{1 7 . 3 7}$ & $\mathbf{9 1 . 6 3}$ \\
\hline
\end{tabular}

\section{Condition -6}

\begin{tabular}{|c|c|c|c|c|c|c|c|c|c|c|c|}
\hline $\mathrm{c}$ & 1 & 3 & 5 & 7 & 8 & 9 & 10 & 12 & 14 & 16 & Total \\
\hline $\mathrm{m}(\mathrm{c})$ & 3.30 & 4.68 & 6.78 & 9.44 & 12.10 & 13.34 & 14.34 & 15.82 & 16.68 & 17.02 & 113.50 \\
\hline $\mathrm{SD}(\mathrm{c})$ & 12.98 & 13.78 & 16.86 & 15.96 & 13.33 & 14.24 & 12.97 & 12.89 & 12.27 & 14.29 & \\
\hline $\mathrm{np}_{\mathrm{e}}$ & $\mathbf{3 . 6 8}$ & $\mathbf{5 . 7 9}$ & $\mathbf{7 . 8 9}$ & $\mathbf{1 0 . 0 0}$ & $\mathbf{1 1 . 0 5}$ & $\mathbf{1 2 . 1 1}$ & $\mathbf{1 3 . 1 6}$ & $\mathbf{1 5 . 2 6}$ & $\mathbf{1 7 . 3 7}$ & $\mathbf{1 9 . 4 7}$ & $\mathbf{1 1 5 . 7 8}$ \\
\hline
\end{tabular}




\section{Appendix}

\section{INSTRUCTIONS - MARKET ENTRY EXPERIMENT}

This experiment is designed to study economic decision making. The instructions are simple. If you follow them carefully and make good decisions, you may earn a considerable amount of money. The money you earn will be paid to you, in cash, at the end of the experiment. A research foundation has provided the funds for this study.

\section{Description of the Task}

This experiment is concerned with the decisions firms make to either enter or not enter newly established markets. In making these decisions, firms must consider the market capacity (the maximum number of firms that can enter a market before losses occur), and the number of other firms (competitors) that may enter the market. If the number of firms that enter a market exceeds the market capacity, competition will be intense, and those firms that enter will face losses. On the other hand, if the number of firms that enter a market is less than the market capacity, competition will be reduced, and those firms that enter will make profits.

You are one of twenty subjects (firms) in this experiment. Communication between subjects is strictly forbidden. You will be asked to make market entry decisions in 50 independent periods (trials). At the beginning of each trial, the computer will display 10 possible market capacities. We denote the market capacity by the letter $\mathrm{c}$. For each value of c, you will be asked by the computer to make one of the two decisions:

$\mathrm{N}$ : Do not enter the market

Y: $\quad$ Enter the market

If you decide to not enter the market, type the letter $\mathrm{N}$ on your keyboard. If you decide to enter the market, type the letter $Y$ on your keyboard.

After all twenty subjects have made their entry decisions, the computer randomly selects one of the values of c, calculates the number of entrants for that value of $c$, and reports your payoff for the trial. Your payoff is determined as follows. For the value of $\mathrm{c}$ selected by the computer, if you decided to not enter the market, you lose 6 francs regardless of the decisions of the other subjects. The value of the franc will be explained later. If you decided to enter the market, your earnings will depend on the capacity of the market and the total number of entrants for this trial. We denote the number of entrants by the letter " $E$ ". If you enter the market, your payoff for the trial will be determined by the following formula:

$$
\text { Payoff }=1+2(c-E)
$$


Please note that if you enter a market, you may earn a positive payoff, if the market capacity is equal to or larger than the number of entrants, or a negative payoff, otherwise.

\section{Example}

The following example illustrates the type of information presented by the computer, and the calculation of your payoff. The computer prompts you to type either " $\mathrm{N}$ " to not enter the market, or "Y" to enter the market for each value of c. Suppose that you made the following decisions for the ten market capacities:

$\begin{array}{llllllllll}1 & 3 & 5 & 7 & 8 & 9 & 10 & 12 & 14 & 16 \\ \mathrm{Y} & \mathrm{N} & \mathrm{Y} & \mathrm{Y} & \mathrm{N} & \mathrm{Y} & \mathrm{Y} & \mathrm{Y} & \mathrm{N} & \mathrm{Y}\end{array}$

After all twenty subjects have made their decisions, the computer informs you of the randomly selected value of $\mathrm{c}$, and your payoff for the trial. Again, suppose that the computer informs you that the market capacity for the trial was 9 . You entered the market for $\mathrm{c}=9$. Your payoff is computed using the formula:

$$
\text { Payoff }=1+2(\mathrm{c}-\mathrm{E})
$$

For your convenience, we have computed payoff amounts (in francs) for all possible combinations of market capacity and number of entrants (see attached table). As you can see, you may win or lose, depending on the number of other entrants. For example, if you entered the market for $\mathrm{c}=9$ and the total number of entrants was 8 , you would earn 3 francs. On the other hand, if 12 firms entered the market, your payoff would be -5 .

This example illustrates the type of information you will receive, and the decisions you will be asked to make. You will play 50 trials during the experiment. All of the trials have the same structure, they only differ from one another in the randomly selected value of c. When the experiment begins, you will be given an initial endowment of 370 francs. Everyone begins the experiment with the same endowment. You may consider a positive as capital or income that an existing firm has already earned. Your subsequent earnings (positive or negative) will be accumulated over all the trials and added to or subtracted from this endowment. The money you earn will be paid to you, in cash, at the end of the experiment at the exchange rate: 1 franc $=\$ 0.25$.

At the end of the experiment, please remain in your seat until your name is called by the experimenter. We will ask you to complete a brief questionnaire, then pay you for your cumulative earnings.

Thank you for your participation. 
MARKET ENTRY PAYOFF TABLE

\begin{tabular}{|c|c|c|c|c|c|c|c|c|c|c|}
\hline & & & & & Valu & & & & & \\
\hline & 1 & 3 & 5 & 7 & 8 & 9 & 10 & 12 & 14 & 16 \\
\hline 1 & 1 & 5 & 9 & 13 & 15 & 17 & 19 & 23 & 27 & 31 \\
\hline 2 & -1 & 3 & 7 & 11 & 13 & 15 & 17 & 21 & 25 & 29 \\
\hline 3 & -3 & 1 & 5 & 9 & 11 & 13 & 15 & 19 & 23 & 27 \\
\hline 4 & -5 & -1 & 3 & 7 & 9 & 11 & 13 & 17 & 21 & 25 \\
\hline 5 & -7 & -3 & 1 & 5 & 7 & 9 & 11 & 15 & 19 & 23 \\
\hline 6 & -9 & -5 & -1 & 3 & 5 & 7 & 9 & 13 & 17 & 21 \\
\hline in & -11 & -7 & -3 & 1 & 3 & 5 & 7 & 11 & 15 & 19 \\
\hline$\Xi$ & -13 & -9 & -5 & -1 & 1 & 3 & 5 & 9 & 13 & 17 \\
\hline$\Xi$ & -15 & -11 & -7 & -3 & -1 & 1 & 3 & 7 & 11 & 15 \\
\hline 10 & -17 & -13 & -9 & -5 & -3 & -1 & 1 & 5 & 9 & 13 \\
\hline 11 & -19 & -15 & -11 & -7 & -5 & -3 & -1 & 3 & 7 & 11 \\
\hline 12 & -21 & -17 & -13 & -9 & -7 & -5 & -3 & 1 & 5 & 9 \\
\hline 13 & -23 & -19 & -15 & -11 & -9 & -7 & -5 & -1 & 3 & 7 \\
\hline 14 & -25 & -21 & $-1^{7}$ & -13 & -11 & -9 & -7 & -3 & 1 & 5 \\
\hline 15 & -27 & -23 & -19 & -15 & -13 & -11 & -9 & -5 & -1 & 3 \\
\hline 16 & -29 & -25 & -21 & -17 & -15 & -13 & -11 & -7 & -3 & 1 \\
\hline 17 & -31 & -27 & -23 & -19 & -17 & -15 & -13 & -9 & -5 & -1 \\
\hline 18 & -33 & -29 & -25 & -21 & -19 & -17 & -15 & -11 & -7 & -3 \\
\hline 19 & -35 & -31 & -27 & -23 & -21 & -19 & -17 & -13 & -9 & -5 \\
\hline 20 & -37 & -33 & -29 & -25 & -23 & -21 & -19 & -15 & -11 & -7 \\
\hline
\end{tabular}




\section{List of Figures}

Fig. 1. Running mean number of actual entries by value of $\mathrm{c}$ : Condition +1 .

Fig. 2. Running mean number of actual entries by value of $\mathrm{c}$ : Condition +6

Fig. 3. Running mean number of actual entries by value of $\mathrm{c}$ : Condition -6 .

Fig. 4. Running mean numbers of MSD scores and correlations by condition.

Fig. 5. Individual strategy profiles: Condition +1 .

Fig. 6. Individual strategy profiles: Condition +6 .

Fig. 7. Individual strategy profiles: Condition -6 .

Fig. 8. Running mean of number of cutoff decision rules by condition.

Fig. 9. Running mean number of switches in decision per period. 


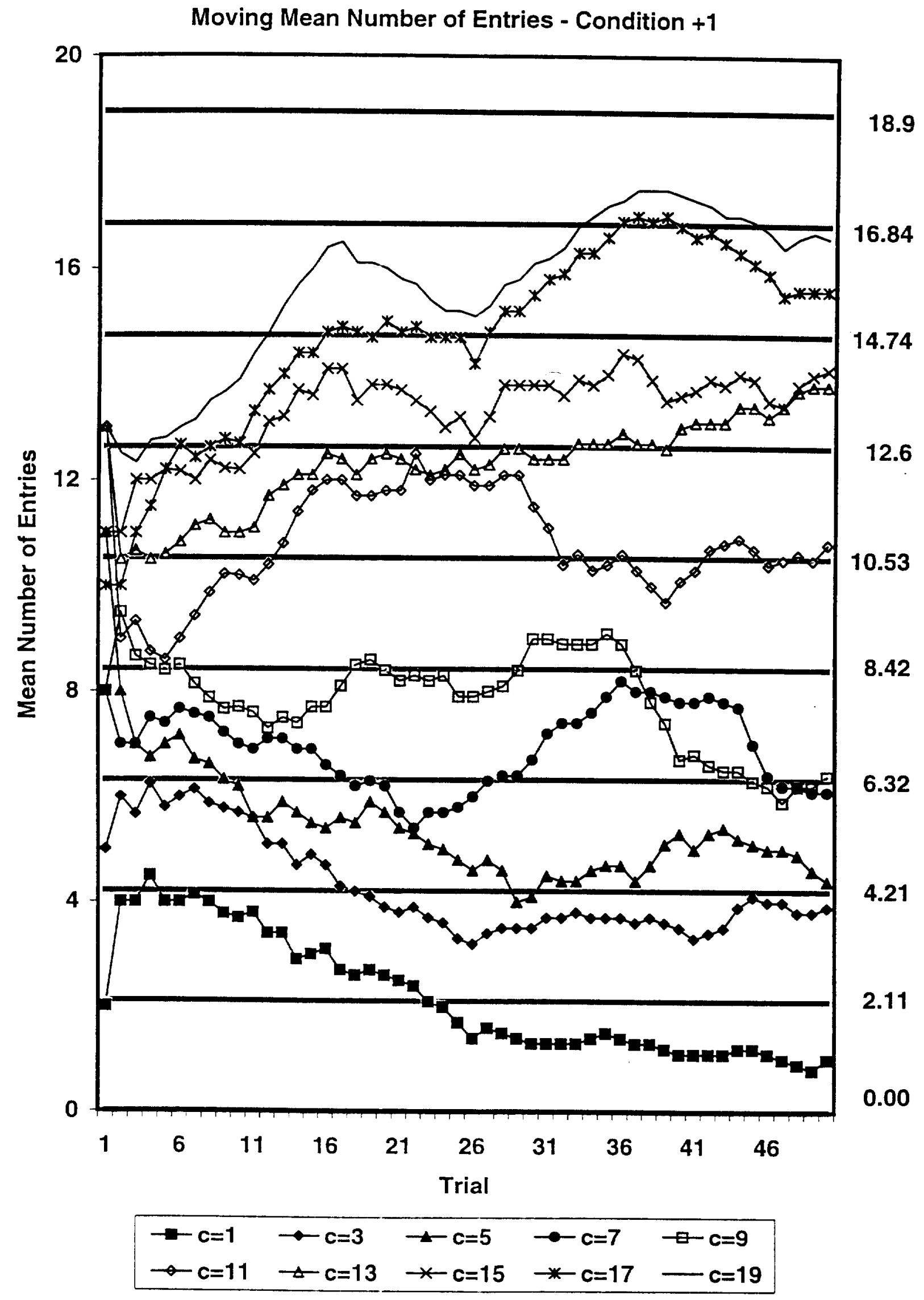

Figure 1 


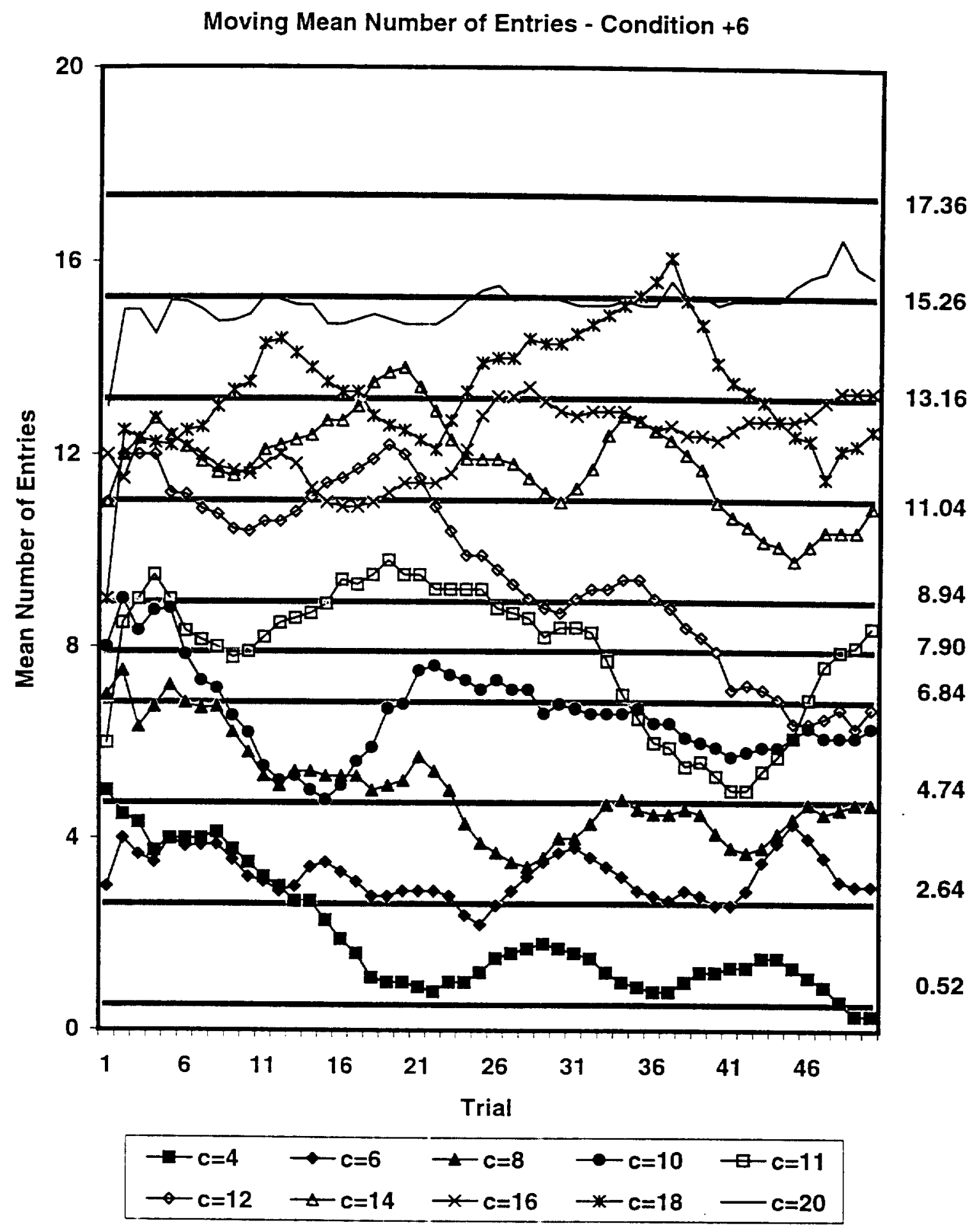

Figure 2 
Moving Mean Number of Entries - Condition - 6

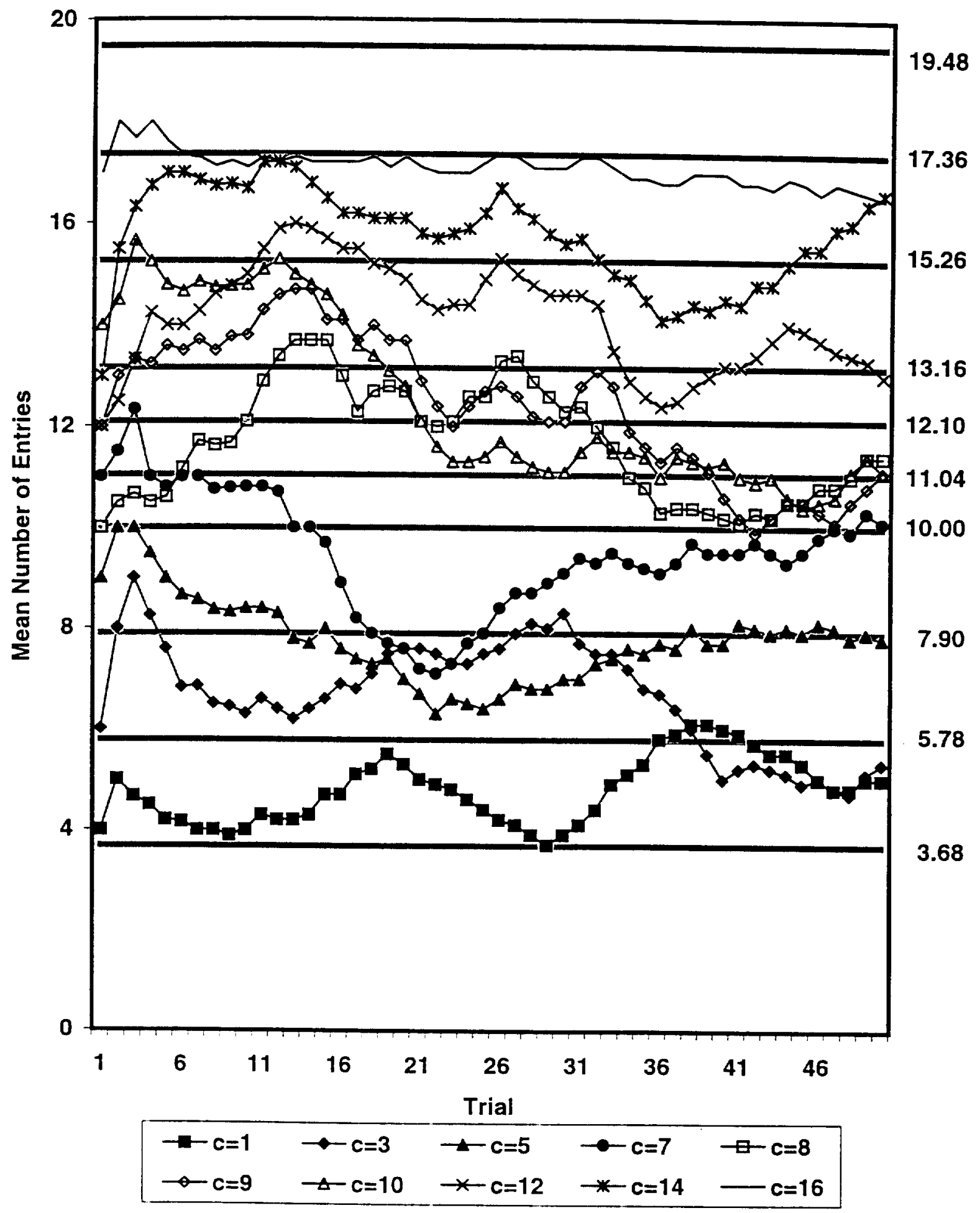

Figure 3 
Running Mean Numbers of MSD Scores and Correlations by Condition
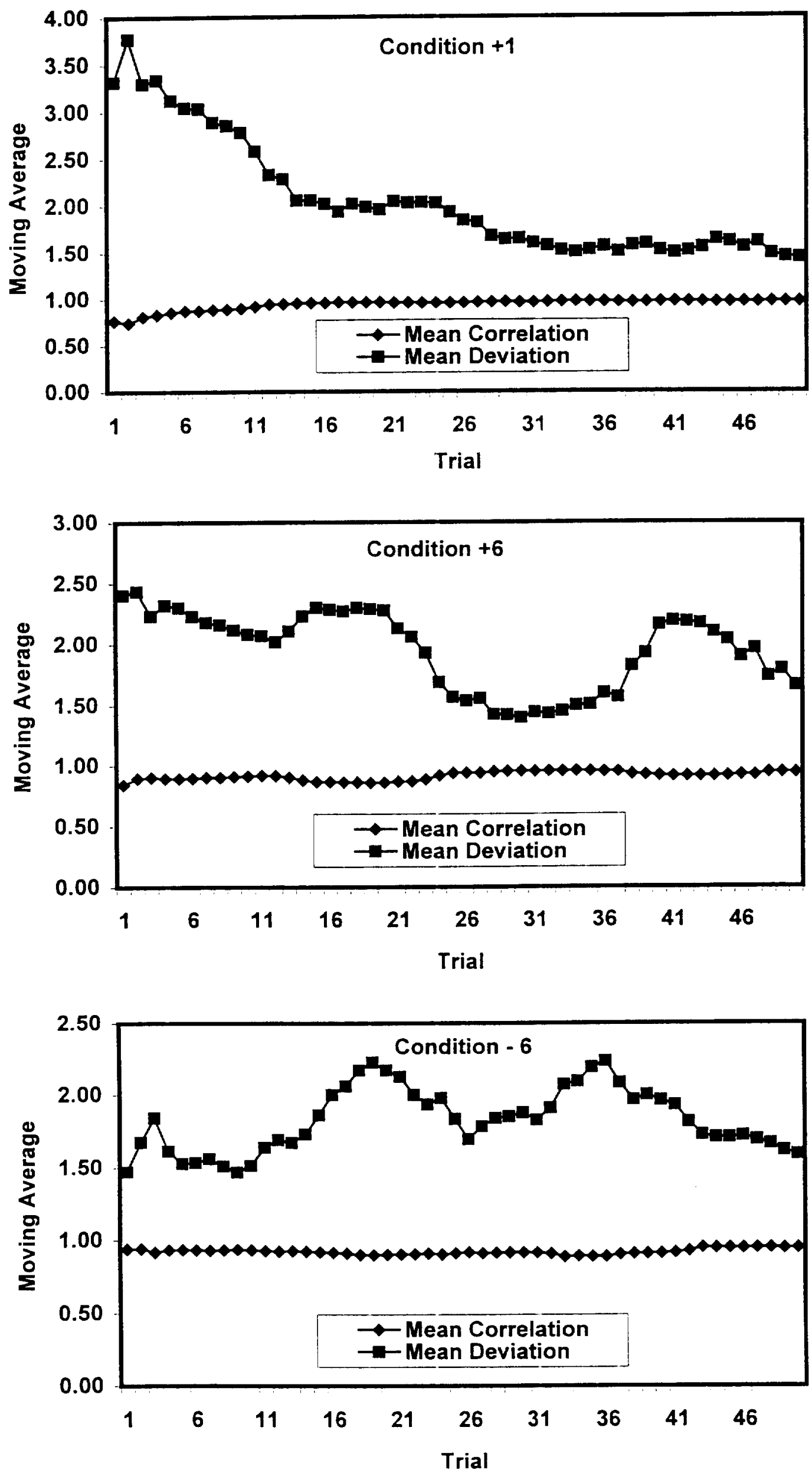

Figure 4 

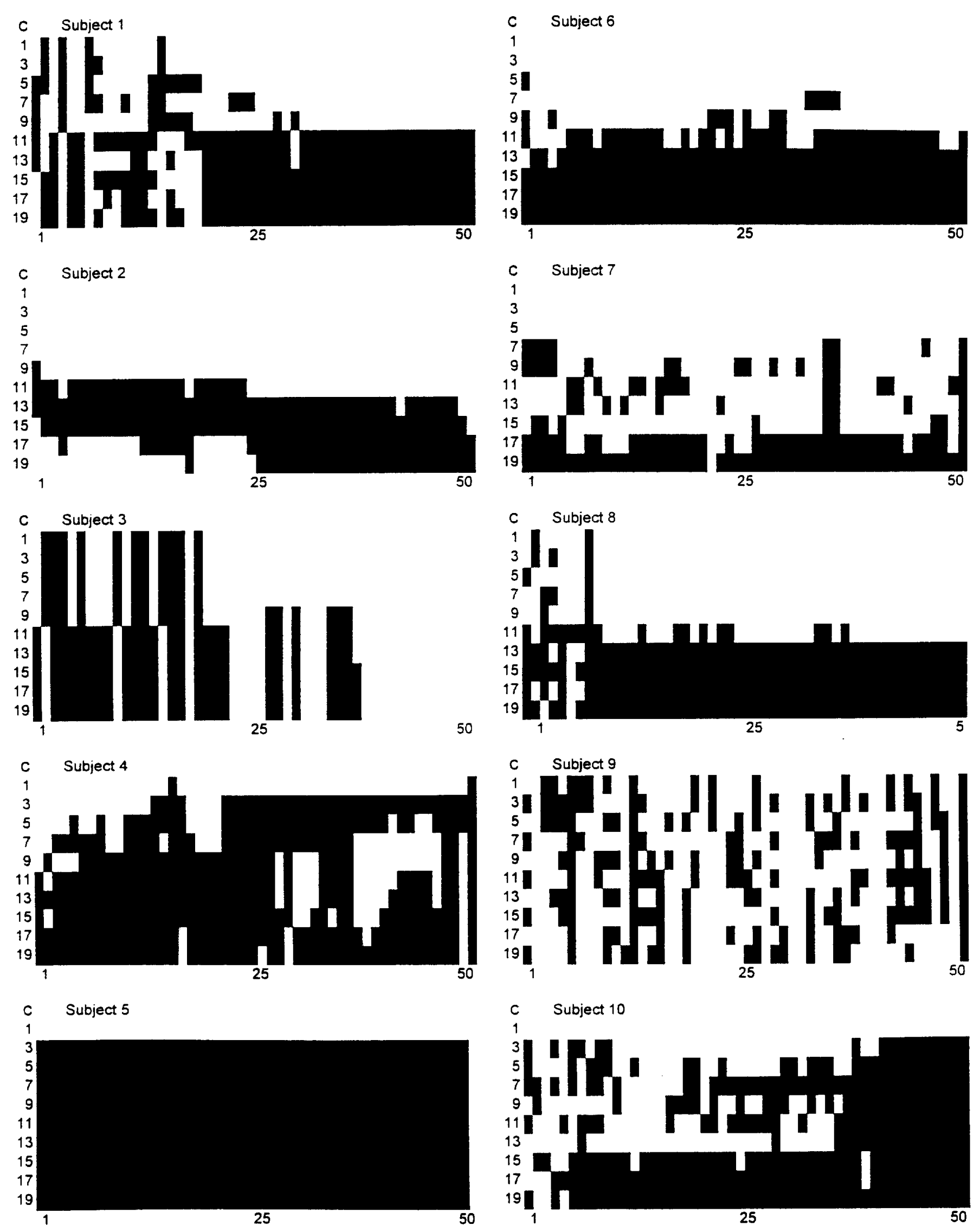

Figure 5A 

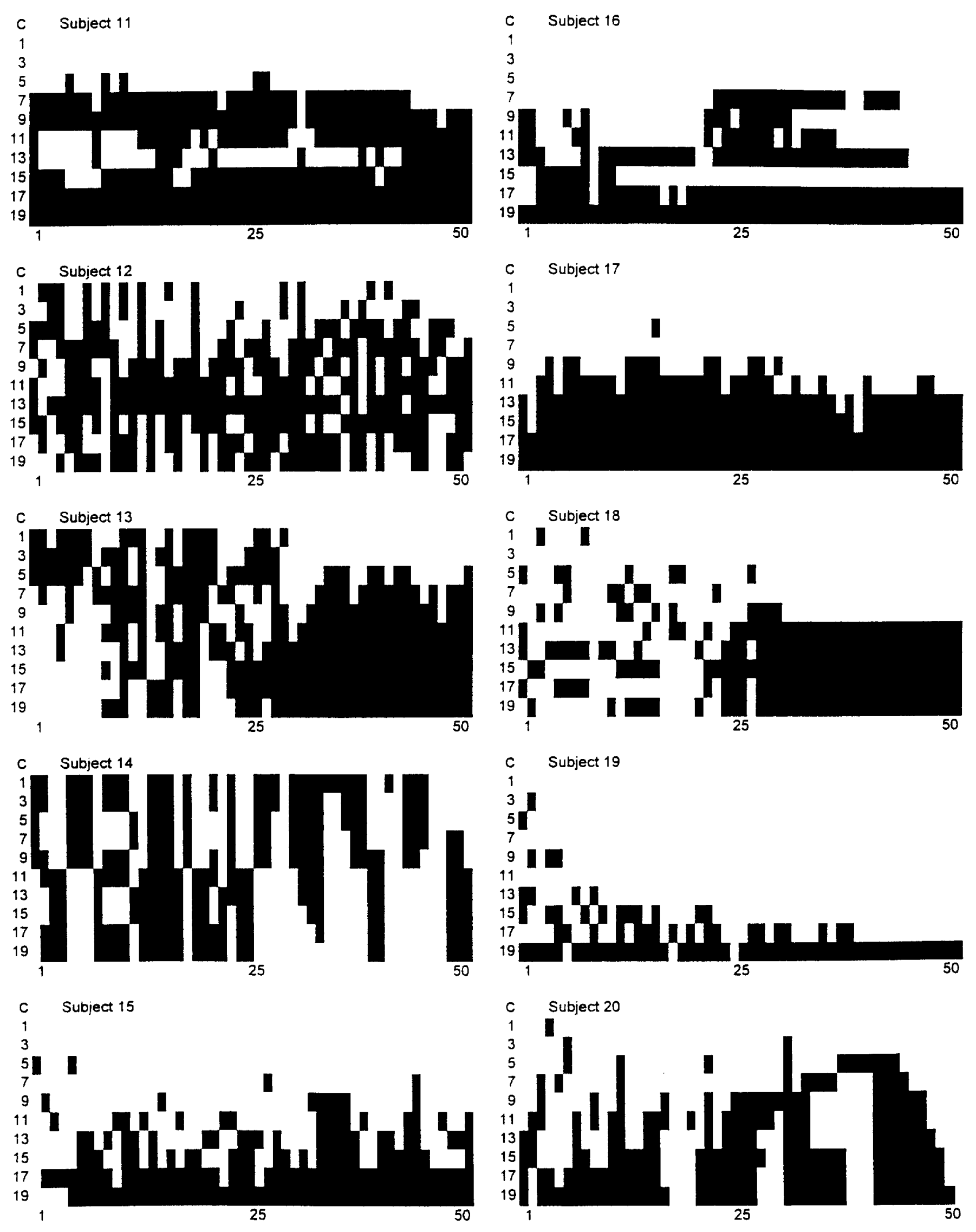

Figure $5 \mathrm{~B}$ 

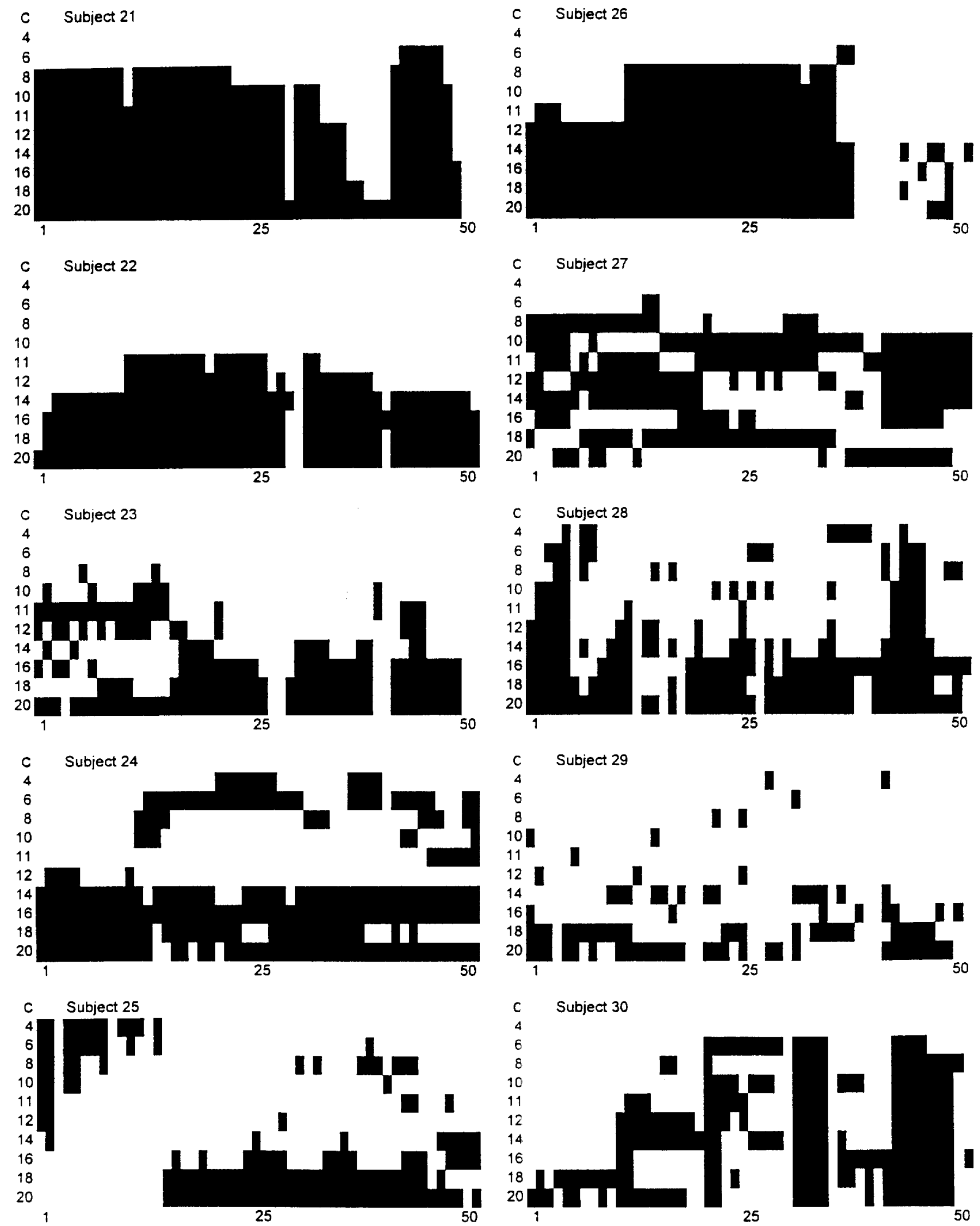

Figure 6A 

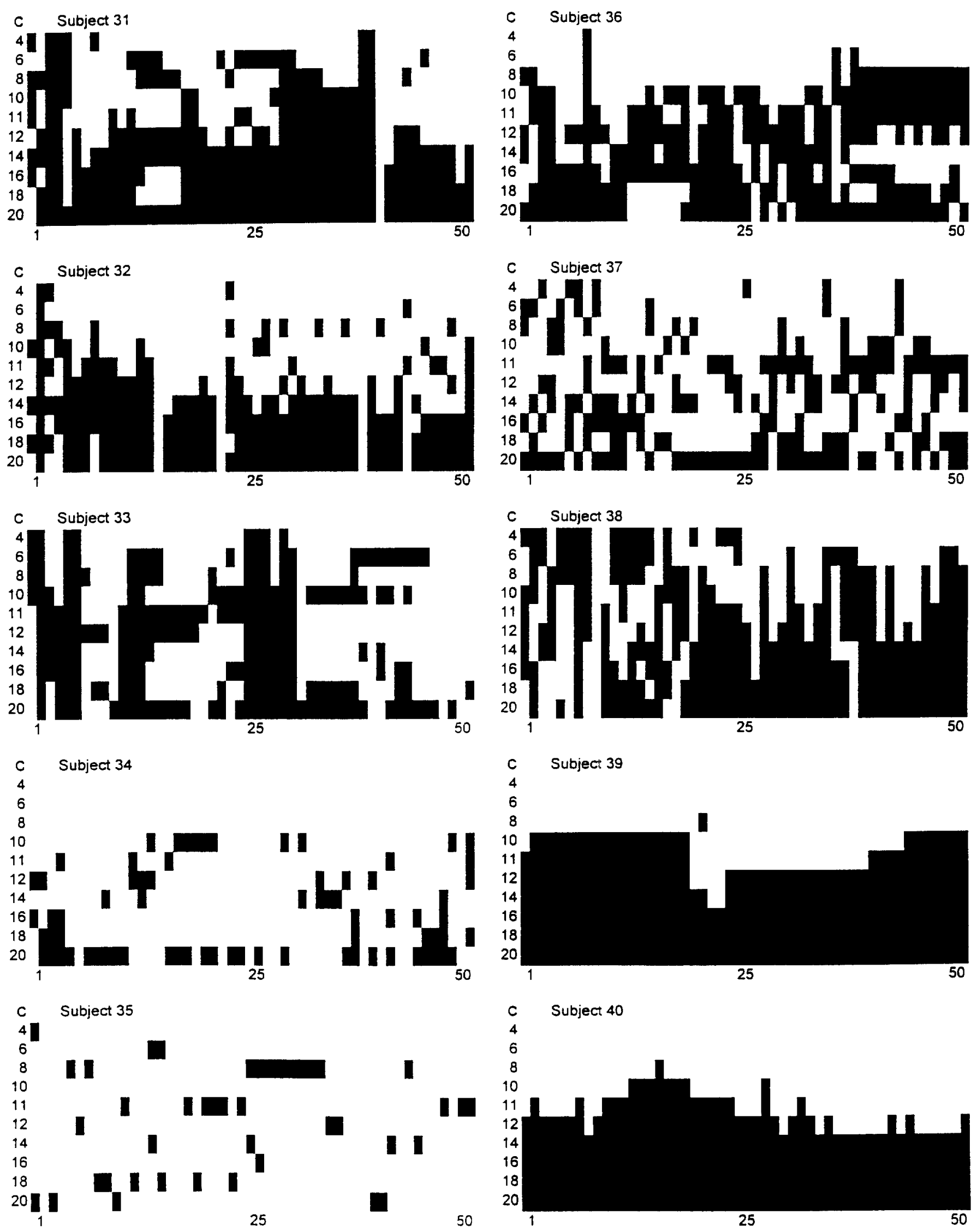

Figure 6B 

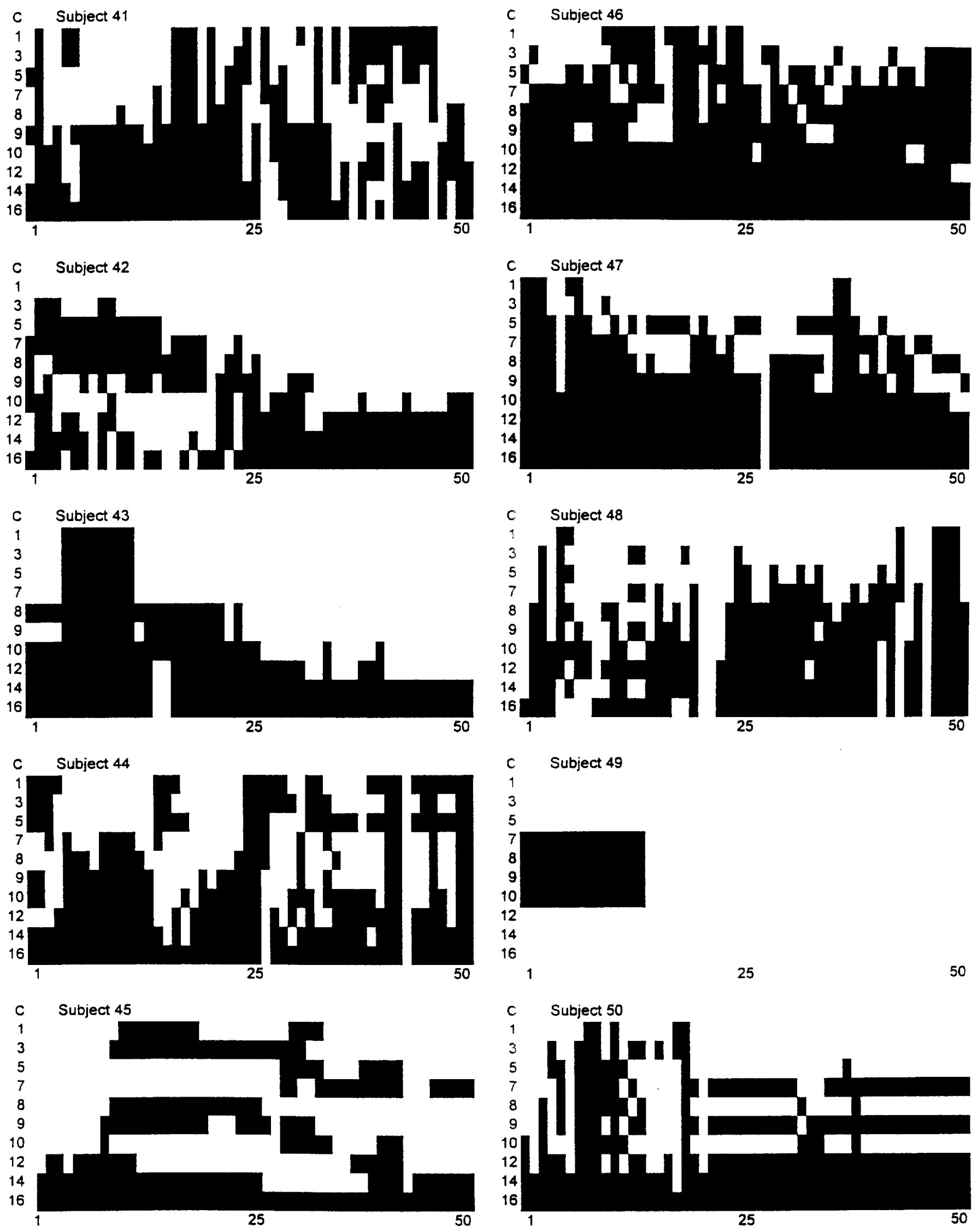

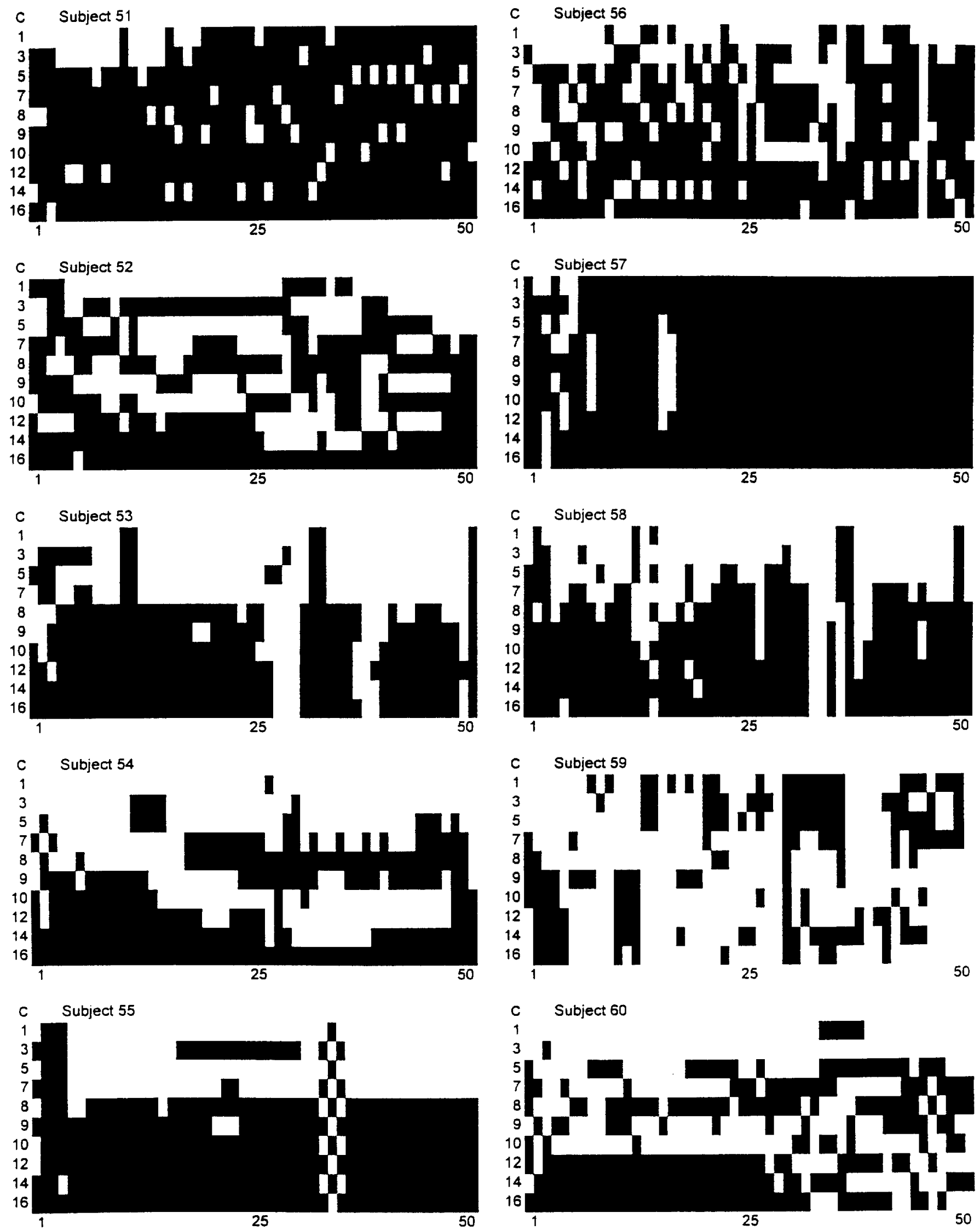


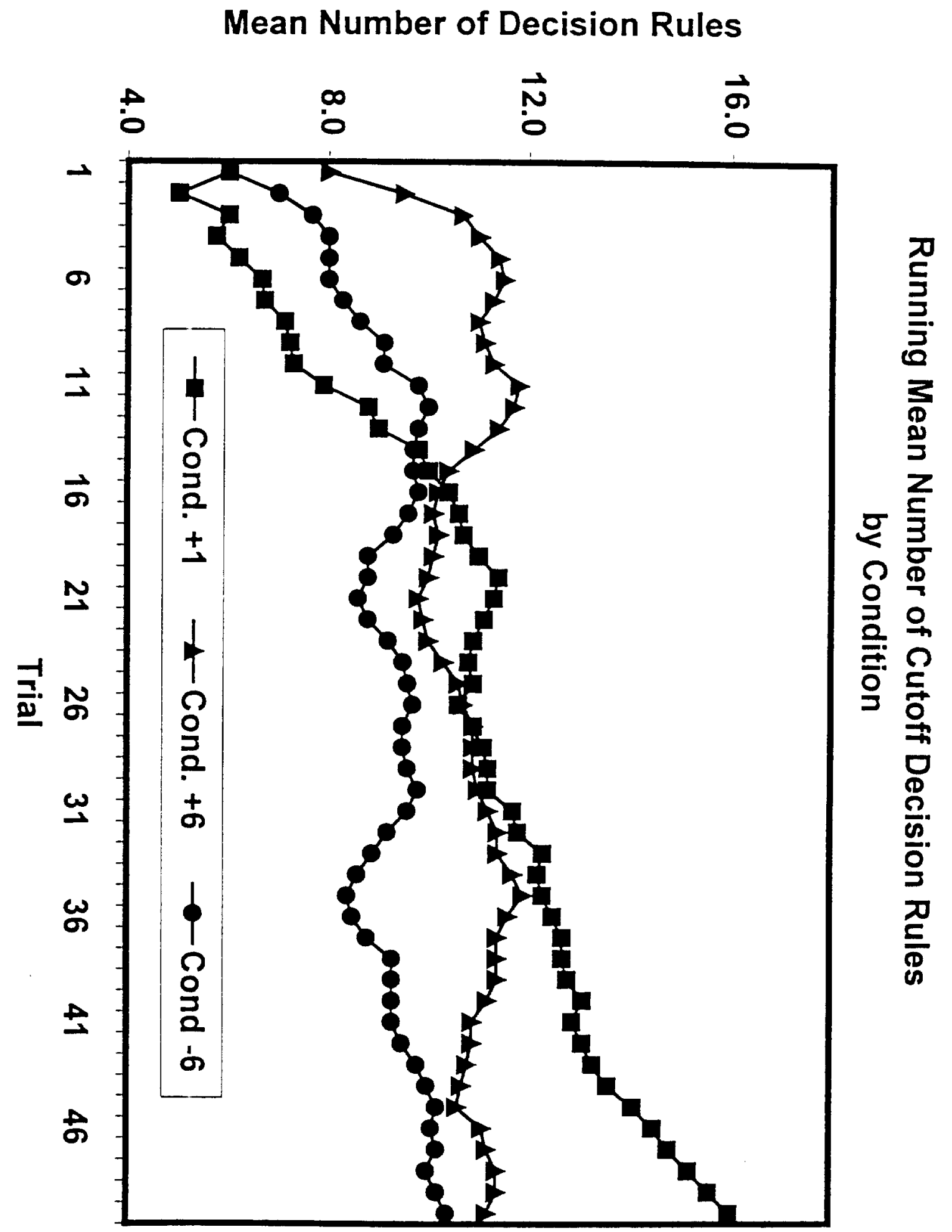


Running Mean Number of Switches in Decision Period
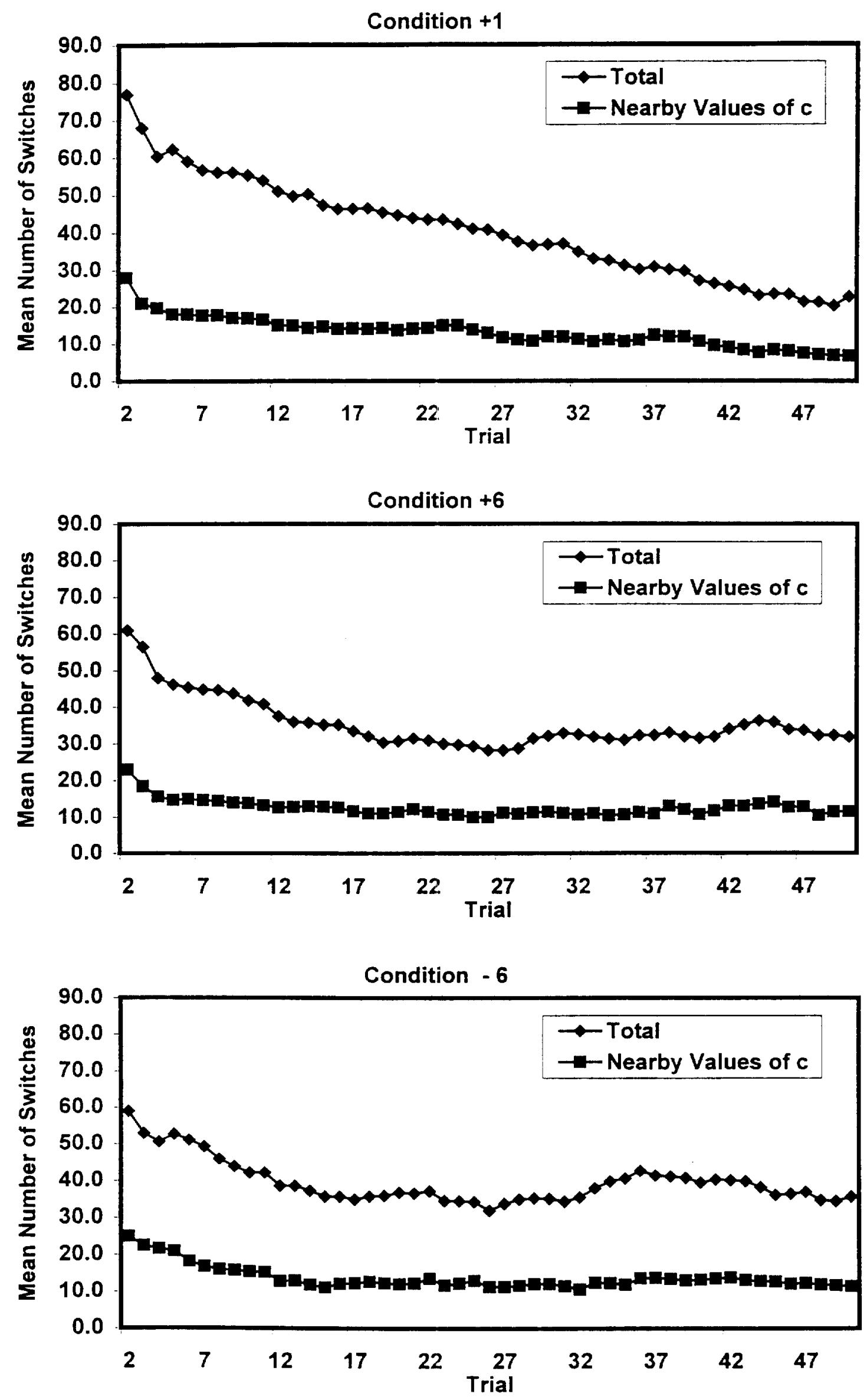

Figure 9 
Please forward your requests for working papers to the following address:

Executive Officer

Department of Marketing

School of Business and Management

Hong Kong University of Science \& Technology

Clear Water Bay

Kowloon, Hong Kong

www: http://www.bm.ust.hk/ mark/

Enquiries: $\quad$ Tel (852) $23587700 \quad$ Fax (852) 23582429 